NBER WORKING PAPER SERIES

THE EFFECTS OF A CENTRALIZED CLEARINGHOUSE ON JOB PLACEMENT, WAGES, AND HIRING PRACTICES

\author{
Muriel Niederle \\ Alvin E. Roth \\ Working Paper 13529 \\ http://www.nber.org/papers/w13529
NATIONAL BUREAU OF ECONOMIC RESEARCH
1050 Massachusetts Avenue
Cambridge, MA 02138
October 2007

Muriel Niederle: Stanford University and NBER, www.stanford.edu/ niederle. Alvin E. Roth: Harvard University and NBER, www.economics.harvard.edu/ aroth/alroth.html. Part of this work was supported by the National Science Foundation. We owe a special debt to Dr. Cody Webb, who first alerted us to the ongoing market failure in the labor market for gastroenterologists. The views expressed herein are those of the author(s) and do not necessarily reflect the views of the National Bureau of Economic Research.

(C) 2007 by Muriel Niederle and Alvin E. Roth. All rights reserved. Short sections of text, not to exceed two paragraphs, may be quoted without explicit permission provided that full credit, including $\odot$ notice, is given to the source. 
The Effects of a Centralized Clearinghouse on Job Placement, Wages, and Hiring Practices Muriel Niederle and Alvin E. Roth

NBER Working Paper No. 13529

October 2007, Revised September 2008

JEL No. J01,J3,J4

\begin{abstract}
New gastroenterologists participated in a labor market clearinghouse (a "match") from 1986 through the late 1990's, after which the match was abandoned. This provides an opportunity to study the effects of a match, by observing the differences in the outcomes and organization of the market when a match was operating, and when it was not.

After the GI match ended, the market unraveled. Contracts were signed earlier each year, at diffuse times, often with exploding offers. The market became less national, more local. This allows us to discern the effect of the clearinghouse: it coordinated the timing of the market, in a way that increased its thickness and scope. The clearinghouse does not seem to have had an effect on wages.

As this became known among gastroenterologists, an opportunity arose to reorganize the market to once again use a centralized clearinghouse. However it proved necessary to adopt policies that would allow employers to safely delay hiring and coordinate on using the clearinghouse.
\end{abstract}

The market for gastroenterologists provides a case study of market failures, the way a centralized clearinghouse can fix them, and the effects on market outcomes. In the conclusion we discuss aspects of the experience of the gastroenterology labor market that seem to generalize fairly widely.

Muriel Niederle

Department of Economics

579 Serra Mall

Stanford University

Stanford, CA 94305-6072

and NBER

niederle@stanford.edu

Alvin E. Roth

Harvard University

Department of Economics

Littauer 308

Cambridge, MA 02138-3001

and NBER

aroth@hbs.edu 


\title{
The Effects of a Centralized Clearinghouse on Job placement, Wages, and Hiring Practices
}

\author{
Muriel Niederle and Alvin E. Roth ${ }^{1}$
}

July 18, 2008

\begin{abstract}
New gastroenterologists participated in a labor market clearinghouse (a "match") from 1986 through the late 1990's, after which the match was abandoned. This provides an opportunity to study the effects of a match, by observing the differences in the outcomes and organization of the market when a match was operating, and when it was not.

After the GI match ended, the market unraveled. Contracts were signed earlier each year, at diffuse times, often with exploding offers. The market became less national, more local. This allows us to discern the effect of the clearinghouse: it coordinated the timing of the market, in a way that increased its thickness and scope. The clearinghouse does not seem to have had an effect on wages.

As this became known among gastroenterologists, an opportunity arose to reorganize the market to once again use a centralized clearinghouse. However it proved necessary to adopt policies that would allow employers to safely delay hiring and coordinate on using the clearinghouse.

The market for gastroenterologists provides a case study of market failures, the way a centralized clearinghouse can fix them, and the effects on market outcomes. In the conclusion we discuss aspects of the experience of the gastroenterology labor market that seem to generalize fairly widely.
\end{abstract}

\section{INTRODUCTION}

The market for almost all entry level positions (called residencies) for new doctors in the United States is mediated by a clearinghouse called the National Resident Matching Program (NRMP). Many other more advanced medical positions (called fellowships, which are the entry level positions for medical subspecialties) use similar clearinghouses, as do medical labor markets in Canada and Great Britain, and a number of other markets (e.g. for many non-medical health care workers in the U.S., for some new lawyers in Canada, etc., see Table II).

These clearinghouses work as follows: Applicants and employers make their own arrangements to interview each other, before submitting rank order lists representing their

\footnotetext{
${ }^{1}$ Muriel Niederle: Stanford University and NBER, www.stanford.edu/ niederle. Alvin E. Roth: Harvard University and NBER, www.economics.harvard.edu/ aroth/alroth.html. Part of this work was supported by the National Science Foundation and the Sloan Foundation. We owe a special debt to Dr. Cody Webb, who first alerted us to the ongoing market failure in the labor market for gastroenterologists, and to our coauthor Dr. Deborah D. Proctor who took the lead in reorganizing the gastroenterology match.
} 
preferences, which are then used by the clearinghouse to centrally determine a matching that specifies which applicant will work for which employer. The algorithms used are generalized deferred acceptance algorithms (Gale and Shapley 1962, see Roth 2002, 2007), which we'll describe in section II.

These clearinghouses correct a set of market failures that often occur in entry level labor markets in which many people seek jobs that all begin at the same time. One source of many problems is that these markets suffer from congestion: since making offers and considering them takes time, there may not be sufficient time for all offers that employers might like to make to in fact be made in a timely way. By the time a candidate has rejected an offer, the next choice candidate may already have accepted an offer elsewhere. This often leads employers to make short duration offers (or even exploding offers, which have to be accepted or rejected virtually immediately), and/or to try to make offers just a little bit earlier than their main competitors. It also means that employers may hesitate to make offers to their most preferred candidates if those offers have only a small chance of being accepted. That is, when choosing which offers to make, congestion forces firms to think not only about how much they like each candidate, but how much each candidate likes them, which can lead to coordination failures. Congestion makes it unsafe for employers to make offers according to their preferences only. ${ }^{2}$

Once it becomes understood that positions in a market may reliably be filled through exploding offers, employers can use them strategically. By making an exploding offer, an employer can impose an ultimatum on a candidate, and make the candidate's effective market potentially very thin, limiting it, in the most extreme case, to this one employer. The use of exploding offers by some employers drives competitors to make offers with short deadlines themselves, even earlier, so as to not lose out on promising candidates. This prevents the market from being thick (see Niederle and Roth 2007).

To summarize, the problems many entry level labor markets face are problems of (i) thickness, (ii) congestion, and (iii) safety. ${ }^{3}$

\footnotetext{
${ }^{2}$ In the market for junior economists, such hesitation can be seen as many departments shy away from interviewing candidates who have applied to them if the candidate seems too accomplished, because they do not know how much the candidate is really interested, as opposed to simply risk averse and applying widely.

${ }^{3}$ See also Roth (2008), which expands on these themes in connection with a different set of markets.
} 


\begin{tabular}{|c|c|c|}
\hline Market & Institution & Description \\
\hline $\begin{array}{l}\text { Graduate School } \\
\text { Admissions }\end{array}$ & Council of Graduate Schools (CGS) & $\begin{array}{l}\text { Exploding offers discouraged, and } \\
\text { acceptances before April } 15 \text { non-binding (see } \\
\text { text) }\end{array}$ \\
\hline $\begin{array}{l}\text { Undergraduate } \\
\text { College } \\
\text { Admissions }\end{array}$ & $\begin{array}{l}\text { National Association for College } \\
\text { Admission Counseling (NACAC) }\end{array}$ & $\begin{array}{l}\text { Binding early decision, non-binding early } \\
\text { action }\end{array}$ \\
\hline $\begin{array}{l}\text { U.S. , Canadian, } \\
\text { and British } \\
\text { Medical } \\
\text { Residencies }\end{array}$ & $\begin{array}{l}\text { National Resident Matching Program } \\
\text { (NRMP), Canadian Resident Matching } \\
\text { Service (CaRMS), various regional } \\
\text { matches in Britain. }\end{array}$ & Centralized clearinghouse \\
\hline $\begin{array}{l}\text { Medical } \\
\text { Fellowships }\end{array}$ & Specialty Matching Services (SMS) & Centralized clearinghouse \\
\hline $\begin{array}{l}\text { Clinical } \\
\text { Psychology }\end{array}$ & $\begin{array}{l}\text { Association of Psychology Postdoctoral } \\
\text { and Internship Centers (APPIC) }\end{array}$ & Centralized clearinghouse \\
\hline $\begin{array}{l}\text { Lawyers } \\
\text { (particularly in } \\
\text { large law firms) }\end{array}$ & $\begin{array}{l}\text { National Association for Law Placement } \\
\text { (NALP) }\end{array}$ & $\begin{array}{l}\text { Principles and Standards for } \\
\text { Law Placement and Recruitment Activities }\end{array}$ \\
\hline $\begin{array}{l}\text { Federal Judicial } \\
\text { Clerkships }\end{array}$ & $\begin{array}{l}\text { Judicial Conference of the United States } \\
\text { (and various ad hoc committees of judges) }\end{array}$ & $\begin{array}{l}\text { Law Clerk Hiring Plan } \\
\text { (http://www.cadc.uscourts.gov } \\
\text { /lawclerk/) }\end{array}$ \\
\hline $\begin{array}{l}\text { Canadian } \\
\text { Lawyers } \\
\text { (articling } \\
\text { positions) }\end{array}$ & $\begin{array}{l}\text { Regional Law Societies (e.g. Law Society } \\
\text { of Upper Canada) }\end{array}$ & $\begin{array}{l}\text { Articling Recruitment Procedures } \\
\text { (centralized match abandoned for 2004-5 } \\
\text { articling term) }\end{array}$ \\
\hline $\begin{array}{l}\text { Japanese } \\
\text { University } \\
\text { Graduates }\end{array}$ & $\begin{array}{l}\text { The Japan Federation of Employers' } \\
\text { Associations (Nikkeiren), Labor Ministry }\end{array}$ & $\begin{array}{l}\text { Establishes guideline dates before which } \\
\text { contracts should not be signed, and rules } \\
\text { about interviewing. }\end{array}$ \\
\hline $\begin{array}{l}\text { Recruitment of } \\
\text { MBA graduates }\end{array}$ & $\begin{array}{l}\text { Individual business school recruiting } \\
\text { offices }\end{array}$ & $\begin{array}{l}\text { Regulations of on campus interviews, dates } \\
\text { and duration of offers, etc. }\end{array}$ \\
\hline $\begin{array}{l}\text { US College } \\
\text { Graduates-on } \\
\text { campus } \\
\text { recruiting }\end{array}$ & $\begin{array}{l}\text { National Association of Colleges and } \\
\text { Employers (NACE) } \\
\text { www.naceweb.org/about/principl.html }\end{array}$ & $\begin{array}{l}\text { Guidelines for good conduct that discourage } \\
\text { reneging of acceptances by students and } \\
\text { undue time pressure of acceptance and } \\
\text { encouragement to renege on another offer. }\end{array}$ \\
\hline $\begin{array}{l}\text { Postseason } \\
\text { college football } \\
\text { bowls }\end{array}$ & Bowl Championship Series (BCS) & Confederation of bowls and conferences \\
\hline Sororities & National Panhellenic Conference & Regulates bidding procedure \\
\hline
\end{tabular}

Table I Some Institutions to regulate offers, acceptances, and rejections 
In a number of markets these problems have become extreme: markets have unraveled, with candidates sometimes being hired several years before employment starts (see e.g. Avery, Jolls, Posner, and Roth 2001 on lawyers, Niederle and Roth 2005 and Niederle, Proctor and Roth 2006 on gastroenterologists, and Roth and Xing 1994 on the labor market for Japanese university graduates among many others). This of course may entail problems other than the lack of thickness. Information about candidates, and even the candidates' preferences over different employers, may not be as accurate long before employment as they will be nearer the time employment actually starts. As a result, many markets have institutions and organizations which aim to regulate the time and way in which offers are made and accepted; see Table I, from Niederle and Roth (2007).

Entry level medical markets, such as for residents and fellows, are prime examples of markets that experienced such problems, and also include many examples of markets that fixed problems of timing by adopting centralized clearinghouses. In these markets, most applicants become available for work at a specific time; e.g. residents take up work upon graduating from medical school, and fellows upon completing their residency. In addition, these are markets in which the employers tend to share some forms of professional organization. Both of these things may facilitate the organization of a clearinghouse, to fix problems that may be common also to other markets.

In this paper we discuss the effects of such a clearinghouse not only on hiring practices (namely the timing of the market, and the kinds of offers that are made), but also employment opportunities, job placement, and potential impact on salaries. A clearinghouse may affect more than just a market's timing. By making offers through a computerized algorithm, congestion problems can be solved, as algorithms operate very fast. Furthermore, as we will describe when we explain deferred acceptance algorithms, when applied to markets of this size, they make it safe for both employers and applicants to reveal their true preferences, no one is harmed by listing a first choice that they are unlikely to get. A deferred acceptance algorithm also allows consideration of any offer, no matter when it is made. Similarly, deferred acceptance algorithms allow applicants to safely wait for better offers, even if they receive an acceptable offer early on. Therefore if there is sufficient participation in the centralized clearinghouse, the market is thick, as 
employers and applicants are all available at the same and the whole market can be considered at once.

The market for gastroenterology fellows provides a natural case study of the effects of a centralized clearinghouse, as this market was organized through a centralized fellowship match, the Medical Specialties Matching Program (MSMP organized by the NRMP) from 1986 to the mid nineties. The arrangement fell apart, and for the next decade the market operated in a decentralized way. It re-established a match in 2006.

These events give us a unique opportunity to discern the effects of such a centralized clearinghouse. We find that, as the market moved from a centralized to a decentralized market, the national market broke up into a collection of more local markets (Niederle and Roth 2003b). Fellowship programs, particularly smaller ones, were more likely to hire their own residents than under a centralized match. Furthermore, the market without a centralized match again unraveled into a market in which, at any specific time, only a subset of hospitals were making offers, which means the market fragmented not only geographically, in space, but also in time (Niederle and Roth 2004 and Niederle, Proctor and Roth 2006). Candidates were once more subjected to very short duration offers, and the market, even after several years of operating without a centralized match, had still not settled down, in that interviews and offers were still made earlier from one year to the next. Finally, although a class action lawsuit (since dismissed) argued that a centralized match suppressed salaries, we did not find that the salaries of gastroenterology fellows, hired in a decentralized way, are any different from other internal medicine subspecialties, either those that use a match, or those that have not used a match for decades (Niederle and Roth 2003a). That is we did not find any evidence that the match affected salaries.

Finally, we consider the obstacles to initiating a centralized match especially in a market that had seen the breakdown of an earlier attempt. In the gastroenterology market, many employers who were themselves willing to delay hiring in order to participate in a match feared that their main competitors would not refrain from hiring candidates early, before a match. We employed some insights from decentralized markets (such as graduate school admissions), and from laboratory experiments, to help the 
gastroenterology professional organizations devise policies that helped to restart the match for gastroenterology fellows, in June of 2006 (Niederle and Roth 2007 and Niederle, Proctor and Roth 2006, 2008).

In the last section of the paper we argue that medical labor markets are not special, many markets suffer from similar problems, namely problems establishing and maintaining (i) thickness, (ii) congestion, and (iii) safety. This can already be intuited from Table I, and we will present some examples in more detail. We also discuss decentralized alternatives to a centralized clearinghouse that some markets have adopted, such as the market for junior economists since 2006.

\section{Deferred AcCePtance Algorithms}

In simple markets, in an applicant-proposing deferred acceptance algorithm, employers and applicants each submit rank order lists of potential matches, that is, each applicant lists which employer is his first choice, his second choice, and so on, and each employer similarly ranks applicants. The algorithm uses these lists to conduct the following operations on behalf of applicants and employers. First, every applicant applies to his/her most preferred employer. Each employer collects all applications, and keeps those it has ranked highest, up to the number of positions it wishes to fill, and rejects all other applications. Applicants who had applications rejected apply to their next choice employer. Employers once more collect all applications (including applications kept from last period), keep the ones they ranked the highest among the applications received so far, and so on, until no rejections are issued (because all applicants are either being held by an employer, or have run out of applications they wish to make, that is, reached the end of their rank order list). At this point the algorithm stops and every applicant is matched to the employer holding his/her application, and receives a contract from that employer. The outcome of such a matching is stable, that is, there exists no applicant-employer pair, not matched to each other, who prefer each other to their current match (given the submitted rank order lists). ${ }^{4}$

\footnotetext{
${ }^{4}$ This is easy to see. Suppose applicant A prefers some employer E to his current match F. Then applicant A must already have applied to $\mathrm{E}$ before he applied to $\mathrm{F}$, and been rejected, at a point in the algorithm at which $\mathrm{E}$ was holding a full set of applications that it preferred to A. Hence if A prefers E to F, E does not return the favor, so no blocking pair exists (Gale and Shapley, 1962).
} 
Furthermore, in simple environments it is a dominant strategy for applicants to submit their true preferences (Roth, 1982, 1985). This is due in part to the fact that any employer remains available until the algorithm stops. That is, applicants incur no disadvantage from applying to employers in the order of their preferences, including applications to very desirable employers who are not likely to accept them. The centralized clearinghouse also makes the market safer for employers; they do not have to accept an applicant before they know that they can't receive a better one (hence the name "deferred acceptance").

A centralized market solves the congestion problem by using an algorithm that produces a stable outcome, makes the market safe, and in turn thick. Any employer can consider any applicant they interviewed and vice versa.

The NRMP developed an algorithm in the early 1950's that is equivalent to a hospital proposing deferred acceptance algorithm (Roth, 1984), and in 1998 adopted a redesigned algorithm, which among other things switched from an employer-proposing version of the deferred acceptance algorithm to one more like the applicant-proposing deferred acceptance algorithm described above. ${ }^{5}$ The more general Roth Peranson algorithm (Roth and Peranson 1999), now used by the NRMP and other stable centralized clearinghouses (see Table II), also allows for the possibility for couples to go through the match together, and for reversions or ordered contracts (in which employers can specify an increased demand for some positions in case other positions aren't filled, see also Niederle, 2007). In general the stable outcome of a firm- and a worker-proposing deferred acceptance algorithm can be different. However, the same set of firms and positions are filled. ${ }^{6}$ And, using rank order lists submitted to the medical residency match, Roth and Peranson (1999) show empirically that, given the submitted preferences, the outcomes were the same for all but about one in a thousand applicants (of which there are approximately 20,000/year). When the market is sufficiently large (Roth and

\footnotetext{
${ }^{5}$ In general, the outcome of the applicant-proposing algorithm is the stable match that every applicant prefers over any other stable match (Gale and Shapley, 1962, see Roth and Sotomayor, 1990 for a survey of the related theory.)

${ }^{6}$ Consider the case of 2 firms and 2 workers, where firm 1 prefers worker 1 over worker 2, while firm 2 prefers worker 2 over worker 1 . Workers have just the opposite preferences, with each worker preferring the firm with the opposite index. Firm 1 will be matched to worker 1 (and firm 2 to worker 2) if we use the agents preferences and a firm-proposing algorithm, while the opposite matching is achieved with a applicant-proposing algorithm.
} 
Peranson, 1999, Immorlica and Mahdian 2005, Kojima and Pathak, forthcoming), it is almost a dominant strategy for all participants, both employers and applicants, to submit their true preferences. 


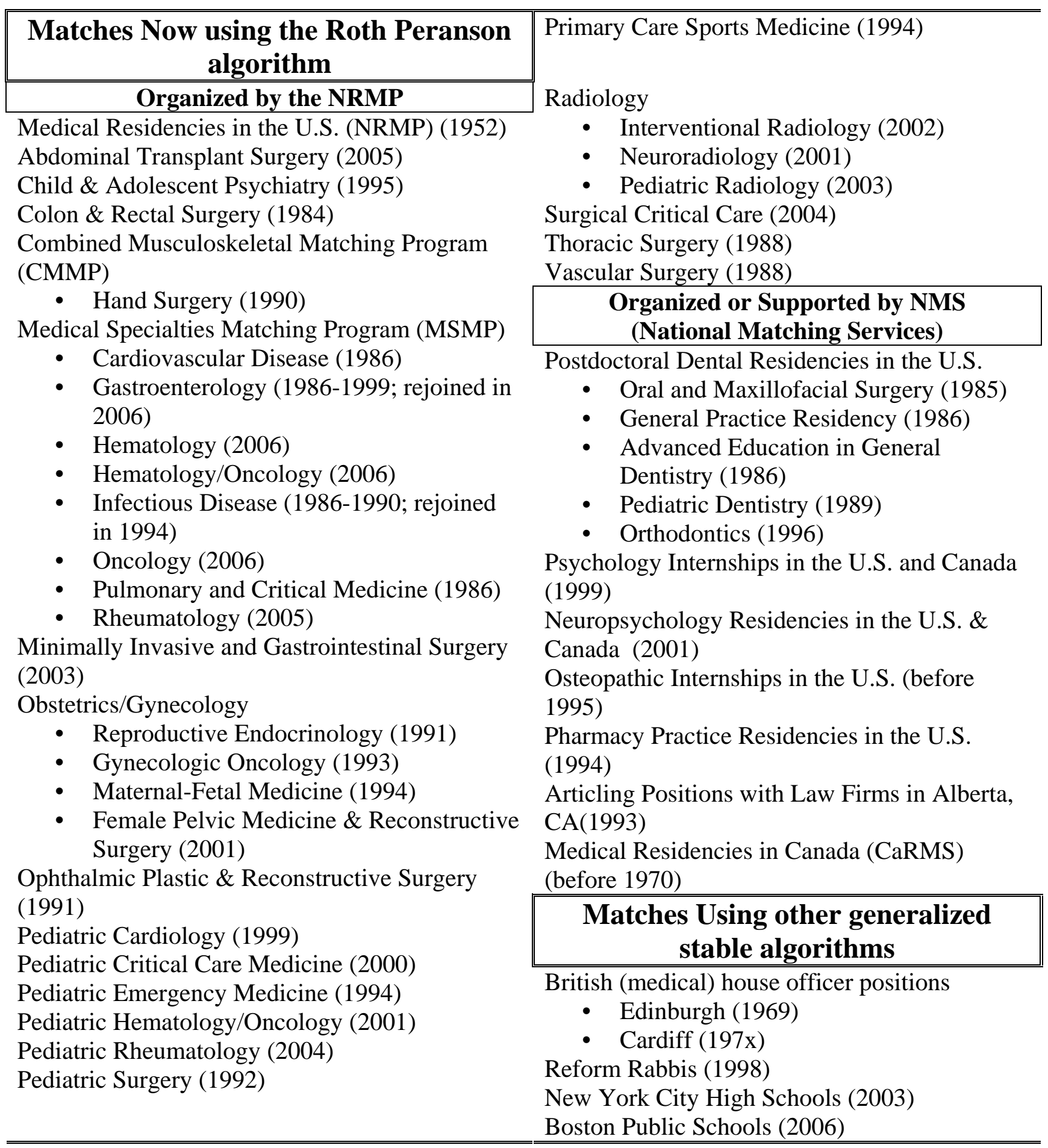

Table II: Stable two-sided centralized clearinghouses that have been studied (and verified to use an algorithm that produces a stable outcome). Year of first use in parentheses. 


\section{THE History OF THE MARKET FOR GASTROENTEROLOGY FELLOWS}

Gastroenterologists typically begin work in their subspecialty three years after graduating from medical school, after having completed a residency in internal medicine (IM). Three additional years as a gastroenterology (GI) ${ }^{7}$ fellow qualifies them for gastroenterology board certification (Before 1996, only two years of fellowship were required.) Internal medicine residents who consider becoming gastroenterologists have many other possible career choices, including practicing as an internist, or pursuing other internal medicine subspecialties, of which gastroenterology is but one.

While the number of GI fellowship positions each hospital can offer has been regulated by the gastroenterology organizations for a long time, prior to 1986 the market for fellows was decentralized. In the 1970's and '80's, hospitals announced positions, received applications, interviewed candidates and made offers at their own pace. The market experienced problems very similar to those experienced by the market of medical interns several decades earlier (Roth 1984, 2003), including the gradual unraveling of appointment dates. Offers for positions came to be made years before employment as a GI fellow would start. In an attempt to halt unraveling, guidelines for the time at which offers could be made were proposed, unsuccessfully. Eventually a centralized labor market clearinghouse was adopted, of the kind used for matching medical students to internal medicine and other residencies.

In 1986, the MSMP (Medical Specialties Matching Program) initiated a centralized match for gastroenterology and other internal medicine subspecialties, conducted one year before employment would start, and so two years into the IM residency. The MSMP uses the same algorithm to match applicants to programs as the NRMP (National Residency Matching Program) that matches medical students to residencies (and since 1998 this is the Roth and Peranson (1999) algorithm). The match for GI fellows operated well, with most non-military programs participating, and over 90\% of participating positions being filled. However after 1996, participation of GI fellows and programs rapidly declined, and the match was formally abandoned in 2000.

\footnotetext{
${ }^{7}$ The abbreviation "GI” stems from the older name for the specialty, gastrointestinal disease.
} 
The collapse of the centralized market allows us to study how a labor market that operated in an organized way, in which interviews were conducted without time pressure, in which offers were made mostly all at once through the centralized match, adapted to the loss of the clearinghouse. Because the lack of the clearinghouse is recent (and because gastroenterology programs were interested in understanding how the new market worked), we were able to survey market participants and observe how the market changed, and how the decentralized market functioned in comparison to when the clearinghouse was in operation. We'll also describe the process by which a new clearinghouse was organized and put into operation in 2006.

\section{THE EFFECTS OF A CENTRALIZED MATCH}

We first study how the market for gastroenterology fellows operated after the match broke down. We describe when interviews were conducted and offers made, what kind of offers applicants received, and the thickness of the market, that is, how many programs were actively hiring at any given time.

We then address whether the decentralized organization of the market produced different outcomes than the centralized clearinghouse, apart from the timing and organization. We will investigate who got matched to whom under the different market organizations and whether salaries were affected. This latter point received some prominence due to an antitrust lawsuit against the match that was dismissed following the passage of new legislation.

\section{III.A. THE DECENTRALIZED MARKET FOR GI FELLOWS: WHAT KIND OF OFFERS WHEN?}

In the late nineties, the market moved from a centralized clearinghouse to a decentralized market: Programs started to match to applicants outside of the match, more specifically, before the match. We will provide an overview of the reasons for the collapse of the match in section IV, but first we describe this new decentralized market.

From the outset, we were faced with a common problem when studying and describing decentralized markets. By their very nature, there are not a lot of data collected on the way the market works. We use two sources of data: the first is FREIDA 
online (http://www.ama-assn.org/ama/pub/category/2997.html), on which many programs announce the time at which they plan to interview. ${ }^{8}$ Second, together with our colleague Dr. Deborah Proctor, and with the sponsorship of the American Gastroenterology Association (AGA) we administered a survey on hiring procedures of gastroenterology programs, in January 2005 (see Niederle, Proctor and Roth 2006). A link to an online questionnaire was sent to the 154 GI fellowship programs accredited by the Accreditation Council for Graduate Medical Education and eligible to participate in a match. We obtained (partial) data from 64 US based programs, a response rate slightly higher than 40\%, with larger and more prestigious programs somewhat overrepresented. The survey focused on the mechanics of how fellows were hired.

We asked when program directors conducted their first and last interview for positions beginning in the summer of 2006. We also asked when they expected to start interviewing for positions beginning in 2007 (at the time of the survey no decision had yet been made to reintroduce the GI fellowship match).

Using data from FREIDA and the survey on interview schedules, Figure 1 shows the timing of interviews for GI fellowship positions, compared to the time of interviews of other internal medicine subspecialties that maintained participation in the match (Niederle, Proctor and Roth 2006). We show the cumulative distribution of programs that started interviewing at any given two-week period. ${ }^{9}$ Not only were GI programs interviewing earlier than subspecialties that still used a match, but they were also interviewing earlier from year to year, even many years after the match collapsed in the late nineties.

\footnotetext{
${ }^{8}$ We accessed FREIDA in 2003 to retrieve data concerning fellowship positions in internal medicine subspecialties starting in 2005, and in the spring of 2002 for GI fellowship positions starting in 2003. We used data from programs whose end date of the interviews occurred after the deadline of the application period. The number of data points we have for the start date of the interview period (end date in parentheses) for positions starting in 2005 is 45 (44) of the 155 GI programs, of the Match specialties we have 83 of the 174 cardiovascular disease programs, 64 of the 139 infectious disease programs, 10 of the 30 pulmonary disease programs, and 52 of the 122 pulmonary disease and critical care programs.

${ }^{9}$ Programs that started their interviews for example from Dec. 23 to January 6 are coded as starting in January, and those that interviewed from Jan. 7 to Jan. 22 as mid-January. This way, programs that start interviewing on the last day of a month, or the first day in the next month - both prominent start times - are coded as starting at the same time.
} 


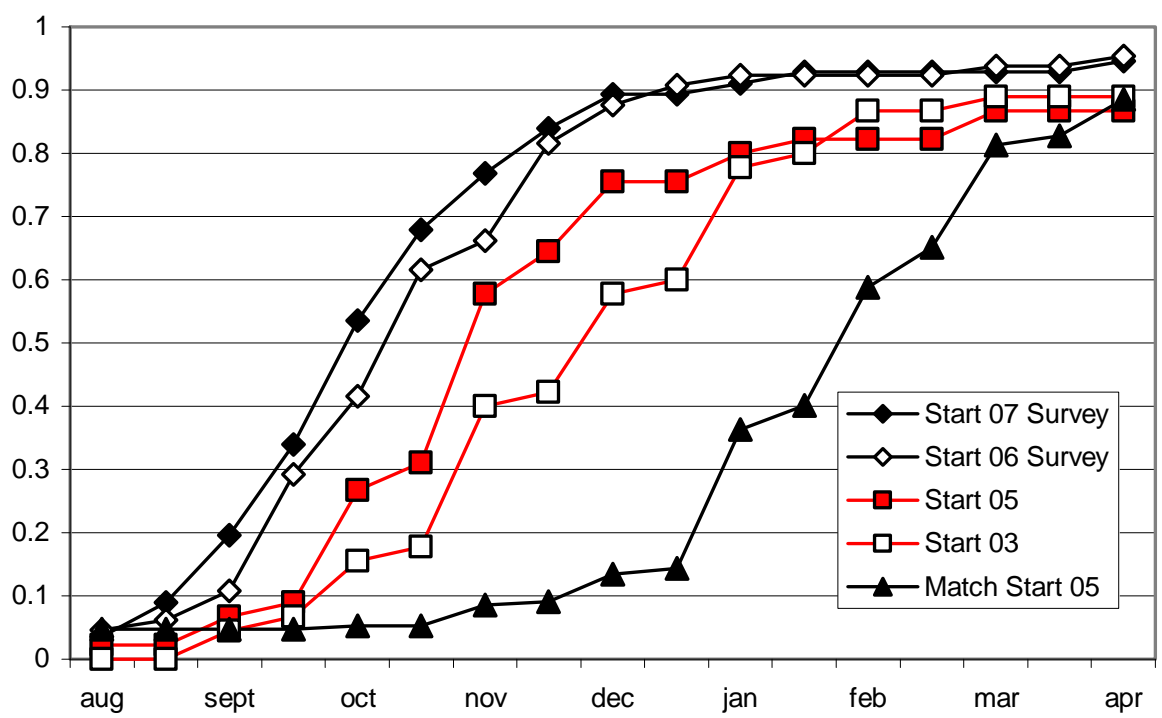

Figure 1

Cumulative distribution of GI and Match programs that started interviewing by the time of any given 2-week period. Match Start 05: interview dates of internal medicine subspecialties that participated in the MSMP for positions starting in 2005. Start 03 and Start 05: Start dates of interviews for GI fellowship positions starting in 2003 and 2005 respectively, from FREIDA (and Niederle and Roth 2004). Start 06 Survey: The replies from the survey of GI program directors to the question of when they started interviewing for 2006 positions. Start 07 Survey: the answers to the question of when GI program directors expected to start interviewing for 2007 positions (without a centralized match) (see Niederle, Proctor and Roth 2006).

The 51 programs that in the survey provided both a start date for interviews for 2006 positions and an anticipated start date for 2007 positions and did not start interviewing before August planned to interview significantly earlier for 2007 positions ( $p<.01$ using a Wilcoxon matched-pairs signed rank test). Of these 51 programs, the programs that planned to interview earlier for 2007 positions are the programs that started interviewing later for 2006 positions. ${ }^{10}$ This is consistent with the view that programs that interview later find that many of the applicants they would have liked to interview have already accepted positions. Furthermore, regression analysis shows that the timing of

\footnotetext{
${ }^{10}$ A regression on the amount of time the program wants to move its interviews ahead (i.e. predicted interview begin next year minus interview begin this year), as a function of when the program started to interview, yields a coefficient of -0.17 (s.e. $0.07, p=.02$ ). The relationship holds even when we control for the number of positions the program is trying to fill or the length of the interview period.
} 
interviews is not correlated with the size of the program (which is a decent proxy for “desirability”, with larger programs being more prestigious).

In the survey, Niederle, Proctor and Roth (2006) not only asked about timing of interviews, but also about the timing and kinds of offers that were extended. For each of the 44 fellowship programs that answered the questions in the survey, figure 2A shows when the first offer was made, and the last offer expired, where (to be very conservative) we assumed that the last offer made was also the one with the longest deadline. Thus the figure shows, for each responding program, a line that begins on the day when the first offer was made and ends when the last offer made would have expired if it was the offer with the longest duration. This provides an upper bound for the time during which the program was actively on the market. Figure 2B provides the proportion of programs that are actively on the market at any given time.

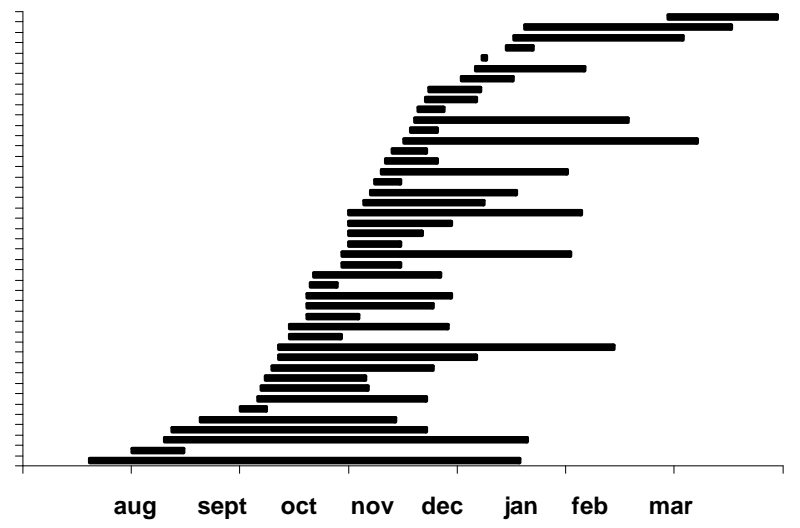

2A

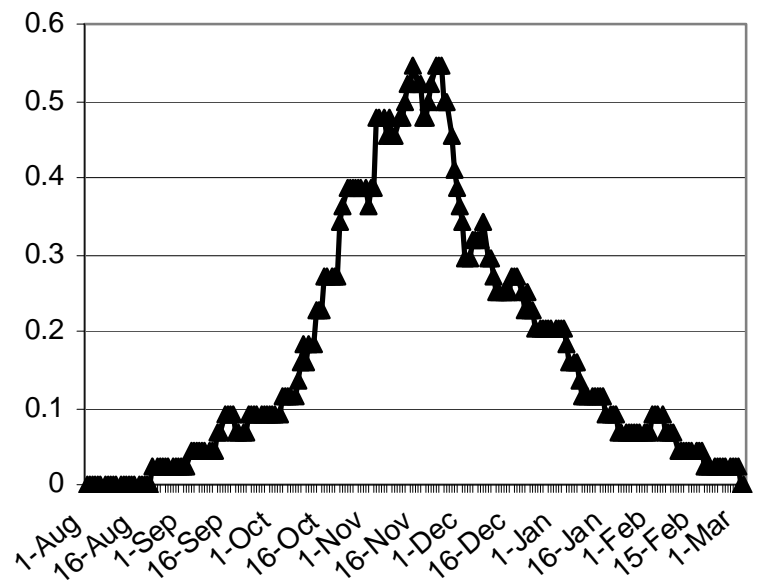

Figure 2

2B

Dates of offers by 44 fellowship programs. A: Each program is represented by a horizontal line, indicating the dates during which it had outstanding offers. B: The proportion of programs that have an outstanding offer on any given day.

Figure 2A shows that by November 15, 11 programs (27\%) had already finished making offers, 12 (25\%) had not yet started, and 21 (48\%) were in the midst. Figure 2B presents the same data another way by showing how many programs had outstanding offers at any point in time. At no point did even $60 \%$ of programs have outstanding offers. So offers 
were dispersed in time, with programs that made offers early often requiring answers before many other programs had begun to make offers.

The hiring process resulted in quite intricate scheduling of interviews and offers. Most programs (53/61) had interviews cancelled, and about half (29/64) made offers before they finished interviewing (of these almost half reported that they did so because of pressure from the market). $43 \%$ of the respondents (28 programs) reported that they speeded up offers because the candidate had another offer, and many other programs reported that in such cases they provided feedback to the candidate about their chance of receiving an offer. Furthermore, 33\% of programs (i.e. 21) considered how likely it was that an applicant would accept their offer when deciding whether to extend an offer. Programs not only decided strategically when and to whom to make an offer, but also on the deadline of offers. More than half the programs (60\%) made at least one offer that required a reply in one week or less, and 95\% required a reply to some offer in two weeks or less. And in fact, $21 \%$ of programs indicated that the longest time a candidate took to respond to an offer was one hour, $60 \%$ report one week at most, and $90 \%$ two weeks at most. Thus the market moved fast. It was not a market in which program directors could interview all the candidates they might wish to before making offers, nor one in which they could safely extend offers to risky candidates, because meanwhile more attainable candidates might take other offers.

That is, the decentralized GI fellowship market made it unsafe to act straightforwardly according to preferences over candidates or employers only. It was a congested, thin market, even though there were (and are) many GI programs and potential GI fellows. As such, the GI market was less competitive than when there was a match, in that competition for each fellow was reduced to a thin slice of employers, and direct competition among fellows for programs was reduced as fellows were hired quickly and could only be considered by very few programs.

\section{III.B. Does a Centralized Match Change the final OUtcome of THE MarKet?}

There were several reasons to think that the thin, early decentralized market that followed the loss of the match might produce different outcomes than the centralized match. 
First, the centralized match yields a stable outcome, i.e. there does not exist a program and resident that mutually prefer each other to their match outcome. (That is, every program could make an offer to any fellow it prefers to its current fellow, only to learn that this new fellow would turn them down, as he or she prefers the current match.) It seems unlikely that the decentralized market as operated by GI programs and fellows can achieve stability, when programs make exploding offers, strategically decide on the candidates to whom to make an offer, and markets are thin. Indeed, theoretical results by Niederle and Yariv (2008) suggest that in general a decentralized market like the market for GI fellows will not result in a stable outcome.

A second reason the decentralized market may yield a different matching is that offers in the decentralized market were made about 6 months to a year earlier than those in the centralized match. Instead of hiring internal medicine residents near the end of their second year, they came to be hired at the beginning of their second year. This means there was less information about residents available when programs decided to whom to make offers.

Finally, there is anecdotal evidence that markets that unravel rely more on informal networks. This can have several reasons: The first is that because candidates are hired earlier, interviews may be less informative, which means program directors have to rely more on recommendation letters, and other sources of information. Clearly, if an internal medicine resident is from the same hospital, and has had a rotation in the GI unit, this unit will have more information on this applicant than on more distant applicants (and more information than other GI programs), and this difference increases as the information on outsiders becomes more noisy. Another reason why markets that unravel may rely more on networks is that the unraveled GI market had more candidates reneging on their acceptance, as internal medicine residents faced offers even earlier than before (and it may be harder to plan two years instead of one year in advance). Hiring fellows within a network may help reduce the enforcement problem, and reduce the likelihood that a candidate reneges on his/her acceptance.

To address whether the market for GI fellows yields a different outcome when it used a centralized match than before or after, we purchased data from the AMA that includes the career path of every living U.S. physician who has completed, or is currently 
completing a GI fellowship, is a board certified gastroenterologist or claims gastroenterology as a specialty (see Niederle and Roth 2003b). The data consist of the year in which each physician graduated from medical school and finished each residency, the location of each residency, and the medical school attended. Of the 15,187 entries we have a total of 9180 fellows who completed a residency and a subsequent GI fellowship in the US after 1977. They do their fellowship in 433 different hospital codes and come from 680 residencies.

Figure 3 shows the mobility of those fellows before, during, and after the fellowship match (i.e. whether they move to a different program, a different city or a different state between their residency and the fellowship). We shall view 1997 as the first year in which the market was no longer effectively organized via the match. That is gastroenterology fellows who got hired in 1997, started employment in 1998 and finished in 2001 will have obtained their job after the match had started to break down. Note that the figure shows each fellow by the date when they ended their fellowship. Since fellowships were required to be 2 years before 1996, but three years since then, and the match operates a year before employment starts, gastroenterologists ending their fellowship in 1989 were the first ones who could have gone through a match, while those ending in 2001 were those who had no functioning match anymore.

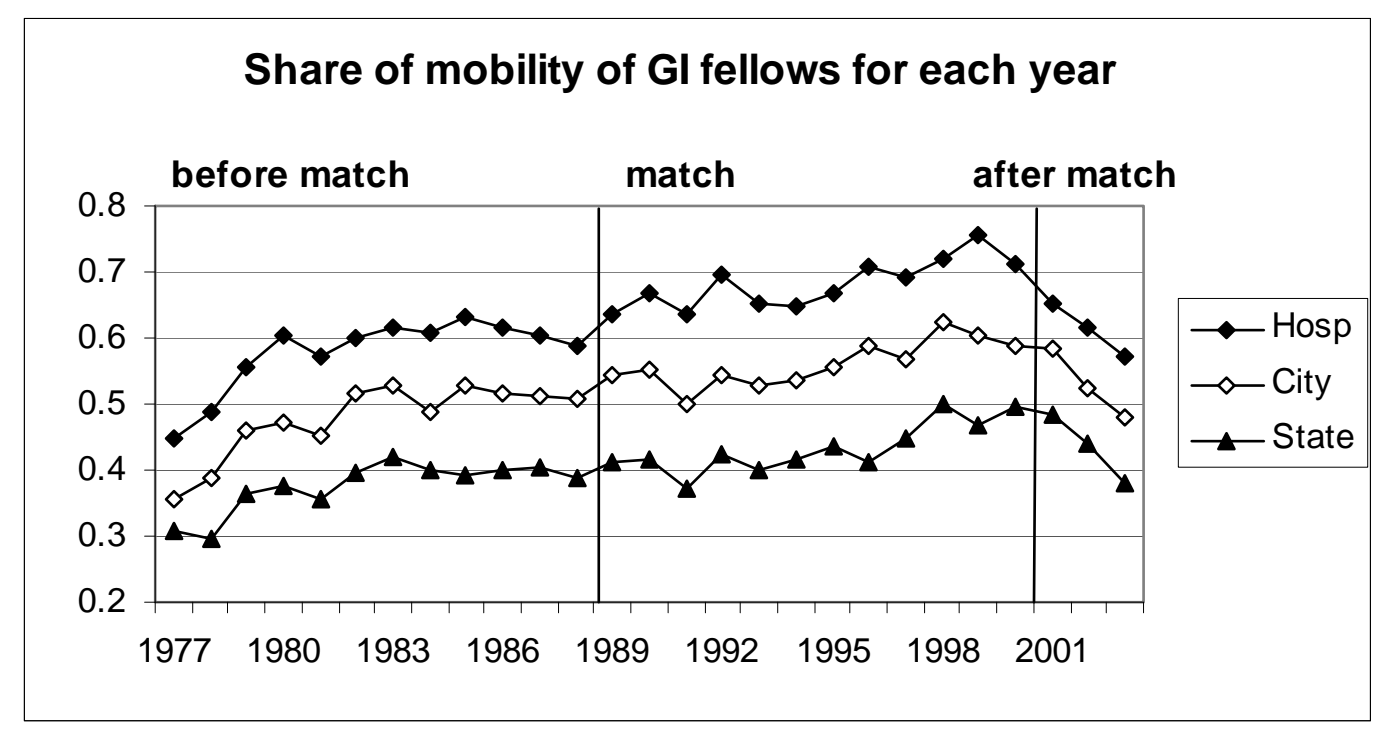

Figure 3: The vertical lines indicate the beginning and the end of the use of the centralized match, measured in year of fellowship completion. 
Before the Match, and after the collapse of the Match, fellows were much more likely to perform their GI fellowship at the same hospital at which they performed their internal medicine residency. There is a statistically significant increase in mobility with the introduction of the Match, and for the hospital and the city level there is a significant decrease in mobility since the demise of the Match compared with the 6 years when the Match was well established. Table III provides the differences across mobility with $p-$ values, where we use a two-sided Mann-Whitney $U$ test, with the proportion of mobility in each year as our data points.

Table III: Differences across Mobility

\begin{tabular}{lcccccc}
\hline \hline \multirow{4}{*}{ Hospital } & $\begin{array}{c}\text { Prematch } \\
\text { - Match }\end{array}$ & $\begin{array}{c}\text { Match 1- } \\
\text { Prematch }\end{array}$ & $\begin{array}{l}\text { Match 2 } \\
\text { Match 1 }\end{array}$ & $\begin{array}{c}\text { Postmatch } \\
\text { - Match 2 }\end{array}$ & $\begin{array}{c}\text { Postmatch } \\
\text { - Match }\end{array}$ & $\begin{array}{c}\text { Postmatch } \\
\text { - Prematch }\end{array}$ \\
& .079 & .052 & .053 & -.096 & -.069 & .009 \\
\multirow{4}{*}{ State } & $(.00)$ & $(.00)$ & $(.02)$ & $(.02)$ & $(.04)$ & $(.52)$ \\
& .059 & .032 & .054 & -.058 & -.031 & .028 \\
& $(.00)$ & $(.02)$ & $(.00)$ & $(.07)$ & $(.19)$ & $(.41)$ \\
& .041 & .014 & .053 & -.026 & 0 & .041 \\
\hline \hline
\end{tabular}

Notes: Prematch: 1980 - 88; match: 1989 - 2000; match 1: 1989 - 1994; match 2: 1995 2000; and Postmatch: 2001 - 2003; Differences in Mobility, with $p$ - values in parenthesis.

Furthermore, we divided our sample into large and small GI fellowship programs. We found that larger programs hired a smaller proportion of local fellows than small programs (at the hospital, city, and state level). The effects of the Match are larger and more significant for large programs than for small ones. ${ }^{11}$

Note that the increase in mobility is gradual, as measured over the first and second six-year periods of the match. This conforms to experimental evidence (Kagel and Roth 2000, and McKinney, Niederle and Roth, 2005) in which the centralized match only gradually becomes fully used by participants.

\footnotetext{
${ }^{11}$ We also controlled for various other possible impacts, such as the fact that because of the consolidation of hospitals, some hospitals may have changed their name, introducing a spurious mobility at the hospital level. To control for this source of bias we eliminated for each hospital the first 3 years of observation (and hence eliminated fellows who may have finished their internal medicine residency in the same hospital when it had a different name). Note that the proportion of GI fellows who finished their GI fellowship by 3 years after their previous residency was always at least $70 \%$. The qualitative results do not change.
} 
An alternative explanation for the increase in mobility during the use of the centralized match is not that the match affects the process, but rather changes the selfselection of interns who aim for a GI fellowship. Specifically, it could be that physicians who are more mobile choose to do a GI fellowship whenever the market operates through a centralized match. To account for that, we can compute for each GI fellow a measure of "mobility" that corresponds to a change in city or state between finishing medical school and the residency they completed just before entering their GI fellowship (this reduces the sample to 6,789 physicians, as we discard all foreign medical graduates). While physicians become less mobile as their career advances, we do not find any evidence that the mobility of GI fellows during the match is driven by an increase in mobile physicians who choose to become gastroenterologists.

Therefore, the decentralized GI fellowship market was not only congested and thin, it also produced different outcomes than when it was organized through a match. With the loss of the centralized clearinghouse, the market broke down into more localized markets (the market became not only thin in time, but also in space).

\section{III.C. Did The Clearinghouse Affect Salaries?}

Another aspect of the matching of fellows to GI programs, is not only who works where, but also under what conditions, specifically, at which salary. This question drew a lot of attention after, in May 2002, sixteen law firms filed a class action law suit on behalf of three former residents, seeking to represent the class of all residents and fellows, arguing that the NRMP violated antitrust laws and was a conspiracy to depress salaries. The lawsuit was against a class of defendants, including the NRMP (which also operates the MSMP), other medical organizations and the class of all hospitals that employ residents. (Jung, et al. v. Ass'n of Am. Med. C., et al., Class Action Complaint, No. 02-CV-00873, D.D.C. May 5, 2002). ${ }^{12}$

\footnotetext{
${ }^{12}$ Another aspect that received considerable attention is the number of hours residents and fellows have to work each week, prompting demand for legislation to limit the hours per week to 80 . There are two reasons we did not focus on hours worked. First, the limitation to 80 hours is in general not binding for fellows, and more importantly, hours come in very different flavors and are not readily comparable across fellowship programs: Some hours are spent on research, patient care and educational activities and may have considerable positive value, while others spent on clerical activities may be a cost..
} 
One way to investigate whether a match affects salaries of medical fellows is to examine comparable medical subspecialties, only some of which use a match. Niederle and Roth (2003a) and (2004) compare salaries of nonmilitary U.S. fellowship programs in all internal medicine subspecialties that require three years of prior residency. The data are from the Graduate Medical Education Library 2002-2003 and 2003-2004 respectively.

\begin{tabular}{lcccccc}
\hline \hline Specialty & Match & $\begin{array}{c}\text { No. of } \\
\text { programs }\end{array}$ & $\begin{array}{c}\text { Mean } \\
\text { salary }\end{array}$ & St.dev & Min & Max \\
\hline PUD & MSMP & 26 & 45,418 & 5,859 & 37,185 & 58,536 \\
CCM & No & 31 & 43,460 & 3,376 & 36,966 & 50,422 \\
IMG & No & 90 & 43,266 & 4,989 & 28,200 & 58,536 \\
HEM & No & 17 & 42,952 & 4,739 & 36,000 & 51,853 \\
ON & No & 24 & 42,650 & 4,922 & 28,200 & 51,853 \\
HO & No & 110 & 42,526 & 4,415 & 32,000 & 58,328 \\
NEP & No & 118 & 42,426 & 4,357 & 30,733 & 58,328 \\
ID & MSMP & 124 & 42,352 & 4,863 & 30,000 & 58,328 \\
CD & MSMP & 153 & 42,288 & 4,246 & 26,749 & 54,450 \\
PCC & MSMP & 111 & 41,973 & 4,268 & 26,916 & 53,463 \\
GE & No & $\mathbf{1 4 2}$ & $\mathbf{4 1 , 8 0 0}$ & $\mathbf{4 , 6 3 8}$ & $\mathbf{2 6 , 0 0 0}$ & $\mathbf{5 8 , 3 2 8}$ \\
END & No & 103 & 41,656 & 4,000 & 33,700 & 53,463 \\
ISM & No & 2 & 41,390 & 1,259 & 40,500 & 42,280 \\
RHU & No & 97 & 41,182 & 4,743 & 28,824 & 58,328 \\
\hline \hline
\end{tabular}

Table IV: For each Specialty the number of programs reporting a positive salary, the mean salary, the standard deviation, the minimum and the maximum salary. The specialties are: PUD: Pulmonary disease, CCM: Critical Care Medicine, IMG: Geriatric Medicine, HEM: Hematology, ON: Oncology, HO: Hematology and Oncology, NEP: Nephrology, ID: Infectious Disease, CD: Cardiovascular Disease, PCC: Pulmonary Disease and Critical Care Medicine, GE: Gastroenterology, END: Endocrinology, ISM: Internal Sports Medicine, RHU: Rheumatology. ${ }^{13}$

Using the 1148 salary data for 2003, a simple regression of the salary on a match dummy yields a constant of $\$ 42,210.76$ (s.e. 168.04, $p=0.00$ ) and a coefficient on the match dummy of $\$ 208.33$ (s.e. 279.82, $p=0.46$ ). That is specialties that use a match do not have significantly lower salaries. ${ }^{14}$

\footnotetext{
${ }^{13}$ We use the data from the Graduate Medical Education Library 2003-2004. We use all internal medicine subspecialties that require 3 years of prior residency, and all non-military programs that record a positive wage and are not in Puerto Rico.

${ }^{14}$ The salaries of GI fellows, while somewhat on the low side, are not significantly different (at any conventional level of significance: lowest is 0.16 ) from either the specialties that participate in a match, or the specialties that do not.
} 
To account for possible effects of hospital size (since match specialties tend to be larger), we want to determine whether, within hospitals, salaries for specialties that use the match are different than for specialties that do not. In the next regression we therefore include a dummy variable for each hospital when regressing the salary on a match dummy (there are 201 different hospitals, of which 165 have both match specialties and specialties that do not use the match). The regression yields a constant of $\$ 42,650$ (s.e. 2372.30, $p=0.00$ ), and a coefficient on the match dummy of $\$ 343.86$ (s.e. 152.60 and $p=0.024)$. That is, within hospitals, the salaries of fellows whose specialty uses a match are higher than those that do not use a match, but the differences are not economically relevant, they are on the order of $1 \%$ of the salary. ${ }^{15}$

That is while salaries may not be very high, empirically it does not appear that using a match affects the salary level in any way.

The lawsuit spurred a number of theoretical papers. Bulow and Levin (2006) provide some support for the lawsuit in a simple theoretical model. They compare a market with impersonal pay (that is a market in which pay is attached to positions rather than depending on which applicant is hired for the position) to a market with perfectly competitive salaries at which each worker is paid his marginal product. They find that in their model a market with impersonal salaries leads to lower average salaries and a more compressed pay schedule. ${ }^{16}$

Subsequent theoretical work has shown that these conclusions about pay compression do not necessarily follow if the model is expanded to include the possibility of firms hiring more than one worker (Kojima, 2007).

There are centralized algorithms that allow for pay to be flexible, and whose outcomes can yield a competitive equilibrium (Kelso and Crawford 1982). The preferences firms and workers submit to a centralized match in such an algorithm consist

\footnotetext{
${ }^{15}$ However, within hospitals, GI fellows earn somewhat less than both the average fellow in a specialty that has a match, and the average fellow in a specialty without a match. While the results are statistically significant, they are not economically significant, they are very small (less than $\$ 1000$ ), no more than $2 \%$ of the salary. Using Graduate Medical Education Library 2002-2003, the salary difference for gastroenterology fellows is only 268.64 and the difference is not significant. Otherwise, the results are similar when we use data from the Graduate Medical Education Library 2002-2003 (see Niederle and Roth 2004)..

${ }^{16}$ Bulow and Levin note that the empirical evidence in Niederle and Roth (2003a) does not bear this out in the actual market data.
} 
of a ranking of each other for any possible pay. For example, a worker would indicate that his first choice is to work for a certain firm at a certain salary, his second choice may be to work for the same firm at a lower salary, and his third choice could be to work for another firm at the higher initial salary, and so on. While the centralized clearinghouse does not use exactly this algorithm, it uses the Roth Peranson (1999) algorithm which allows firms to list alternative positions at different salaries, and to express preferences for some workers in only some positions. This algorithm, in the environment studied by Bulow and Levin (2006), can yield competitive outcomes (Niederle, 2007). A centralized clearinghouse using the Roth Peranson (1999) algorithm therefore does not per se reduce price competition.

How would a decentralized market yield competitive wages? In general, the assumption is that if a wage is below the competitive level, either the worker himself, or some other firm becomes aware of an arbitrage opportunity, which would eventually lead to a competitive outcome. This was implicitly the motivation for the lawsuit: the notion was that without a match, residents would receive many offers, and bargain until they receive their competitive outcome. We already showed that in the market for internal medicine residents seeking GI fellowships, the decentralized market is far from one in which residents can safely wait for multiple offers. Instead, the market is characterized by exploding offers made at very dispersed times that do not allow residents to seek out multiple offers simultaneously.

We studied empirically whether the limited offers that can be obtained simultaneously lead to bargaining (Niederle, Proctor and Roth, 2006). We asked gastroenterology program directors in the survey whether they offered different terms to different fellows, and whether wages were adjustable. Out of 63 program directors, all but 4, (i.e. 94\%) offered the same salary to all their fellows. Furthermore, all but 4 (although not all the same 4 programs) offered the same hours on call. While eighteen of the 63 programs (29\%) offered different fellows different amounts of time for research; all but 3 of these programs formally differentiated the kinds of fellows doing different jobs (i.e., they had at least 2 kinds of fellows). That is, not many program directors offered different contracts to different fellows they hired in the same year (and remember that we oversampled the larger programs, which have more than one fellowship per year). 
All program directors responded that offers were not adjusted in response to outside offers and terms were not negotiable.

In general, markets with impersonal pay may be more common than standard models would suggest. ${ }^{17}$

Thus, while different programs offer different salaries and terms, and while program directors respond in many other ways to the contingencies that arise in the course of the hiring process (such as adapting the timing and length of their offers), it does not appear that they adjust the terms of their offers to the situations of individual candidates. Rather, as the market for GI fellows abandoned the match it seems to have become less competitive, in the sense that at each point in time, residents did not face the whole market, but only the smaller set of programs that made offers at that time. And indeed, some fellows lamenting the loss of the match did so for that reason. ${ }^{18}$

A centralized match halted unraveling and solved congestion, allowing for a thick GI fellowship market, in which programs and fellows could safely make and consider their offers. This led to a more national market with increased mobility of GI fellows. Furthermore, there is no theoretical or empirical evidence that a clearinghouse using the Roth Peranson (1999) algorithm adversely affects the terms of the contracts.

Reflecting these considerations, President George W. Bush signed into law, as an addendum to the Pension Funding Equity Act of 2004, legislation that included a Congressional finding that "Antitrust lawsuits challenging the matching process, regardless of their merit or lack thereof, have the potential to undermine this highly efficient, pro-competitive, and longstanding process ... ." The legislation goes on to "confirm that the antitrust laws do not prohibit sponsoring, conducting, or participating in a graduate medical education residency matching program, or agreeing to do so ... ." Following this legislation, the antitrust suit was dismissed.

\footnotetext{
${ }^{17}$ Wages seem to be also rather inflexible when it comes to junior hiring of professors. Assistant professors who start in the same department and the same year often receive almost the same salary, and some departments make that a policy.

${ }^{18}$ Gastroenterology fellows Bauer, Fackler, Kongara, Matteoni, Shen and Vaezi commented in 1999 on the effects of the loss of the match. "Of recent concern is the deterioration of the match process for candidates applying for fellowship positions over the past two years. Our junior colleagues are concerned that they may not be able to wait safely to interview with the institution of their choice while a position is offered elsewhere early in the decision process. The absence of the match benefits the programs a great deal more than their applicants.”
} 


\section{Changing The Market Organization}

The market for GI fellows raises two kinds of questions about the organization of a market. The first is why this match broke down (and why failures of centralized clearinghouses that produce stable matchings are so rare). The second is how can an unraveled, decentralized market be reorganized through a clearinghouse.

\section{IV.A. WHY DID THE GI MATCH FAIL, AND WHY ARE THESE FAILURES SO RARE?}

The market for GI fellows is among many markets that introduced a centralized match to overcome problems of unraveling and congestion. Empirically, markets that use a centralized algorithm that produces a stable outcome are more successful in remaining in use than those that do not. Of particular interest in this regard are the centralized clearinghouses used in various regions in the British National Health Service. In the 1960's, these markets suffered from the same problems as the American market for medical interns in the 1940's (successfully solved by the centralized match, the NRMP). A Royal Commission recommended that each region of the NHS use a centralized clearinghouse, and the various regions in Britain each invented their own algorithm, of which only some were stable. ${ }^{19}$ Clearinghouses that produced stable matches succeeded, while others mostly did not (Roth, 1991). However, considering all markets that use centralized clearinghouses, this correlation isn't perfect, some matches with algorithms that don't provide stable matches survive, and some stable match algorithms fail. Furthermore, there are more differences between markets than simply the algorithms they use. Thus controlled experiments can help clarify what is going on.

\footnotetext{
${ }^{19}$ An example of unstable algorithms, are "priority algorithms" that use the exact place in which firms and workers rank each other. For example, Roth $(1990,1991)$ observed clearinghouses in Newcastle and Birmingham that first matched all firms (medical practices) and workers that listed each other first. After all such "1-1" pairs, 1-2 pairs were matched, i.e. pairs in which the workers list the firm first, and the firm lists the worker second, followed by 2-1 pairs, and so forth. At each step, matched firms and workers are removed, and the order of removal is given by the product of the worker-firm ranking, where in case of the same products priority is given to workers. This can create unstable outcomes. Consider a firm $\mathrm{F}$ and a worker A that both list each other $4^{\text {th }}$, which gives them priority 16 . Now assume some other worker B lists firm $\mathrm{F}$ first, and the firm $\mathrm{F}$ lists him $15^{\text {th }}$. Nonetheless this gives them priority 15 , and hence firm $\mathrm{F}$ will be matched to worker B over worker A, who may receive some other lower ranked firm that lists him highly, in which case worker A and firm F would be a blocking pair, in that they rather be together than with their current matches.
} 
Kagel and Roth (2000) report an experiment that compares two small unraveled markets in the laboratory. In one, the stable matching mechanism observed in Edinburgh was introduced, while in the other the unstable mechanism used in Newcastle was used. In these otherwise identical sets of markets, the markets that used a stable algorithm adopted the clearinghouse successfully, and continued to use it. The markets that used the Newcastle mechanism that does not produce stable outcomes did not adopt the clearinghouse successfully, and the markets continued to experience offers and acceptances before the operation of the centralized clearinghouse.

Having a stable algorithm thus seems to be an important factor for a centralized clearinghouse to perform well, and continue to be used, and, as Table II shows, most of these have been successfully in operation for years. The market for GI fellows is unusual, in that it used a centralized clearinghouse with a stable algorithm, and then, in the late nineties, started to unravel.

These events seem to have been set in motion in 1993-1994, when, in the midst of general discussions of health care reform, Gastroenterology subjected itself to a manpower analysis. The resulting study was published in 1996 (Meyer et al 1996). Its main conclusions were that the US health care system and gastroenterologists would benefit from a reduction in gastroenterology fellowship programs. The Gastroenterology Leadership Council endorsed a goal of $25 \%$ to $50 \%$ reduction in the number of GI fellows over 5 years. Furthermore, an additional year of training was mandated: starting in the summer of 1996, three years of training were required to be eligible for board certification as a gastroenterologist, instead of two.

That is, in 1996 the supply of gastroenterology fellowships was sharply reduced, and the time needed to become a gastroenterologist was increased by a year (i.e. the cost of becoming a gastroenterologist was increased, although some three-year fellowship programs had already existed before 1996).

However, the announced (and hence expected) reduction in supply was accompanied by an even larger reduction in the number of residents who applied for GI fellowship positions. This seems to have been the start of the demise of the match. In 1996, for the first time, and despite the reduction in the number of positions offered, there were fewer applicants for GI fellowship positions than there were positions offered in the 
match. This resulted in a record low fill rate: only $74.8 \%$ of the positions in the match were filled through the match that year.

The next year, 1997, saw a sharp decline in the percentage of positions in the match. In particular, table V (from Niederle and Roth, 2003b) describes how withdrawal of positions from the match (as programs and applicants reached agreements outside of the match) preceded the formal demise of that match. Withdrawals went from about 5\% in 1996 to $16 \%$ in 1997 , to $44 \%$ in 1998 , to $60 \%$ in 1999 , in each case followed by a sharp reduction the following year in the number of positions even advertised in the match, and after 1999 the match was formally abandoned, having already become moribund, as almost all positions were filled outside of the match. ${ }^{20}$

\begin{tabular}{cccccccc}
\hline \hline Yr & $\begin{array}{c}\text { Positions } \\
\text { advertised }\end{array}$ & $\begin{array}{c}\text { Percent } \\
\text { With- } \\
\text { drawn }\end{array}$ & $\begin{array}{c}\text { Positions } \\
\text { in Match }\end{array}$ & $\begin{array}{c}\text { Percent } \\
\text { Matched }\end{array}$ & $\begin{array}{c}\text { Number } \\
\text { of } \\
\text { Programs }\end{array}$ & $\begin{array}{c}\text { Number } \\
\text { of } \\
\text { Applicants }\end{array}$ & $\begin{array}{c}\text { Applicants } \\
\text { per position } \\
\text { in Match }\end{array}$ \\
\hline '92 & -- & -- & 377 & 96.6 & 160 & 658 & 1.75 \\
'93 & 374 & -6.7 & 399 & 94 & 173 & 642 & 1.6 \\
'94 & -- & -- & 369 & 93 & 169 & 591 & 1.6 \\
‘95 & 351 & 4 & 337 & 88.7 & 171 & 433 & 1.3 \\
'96 & 313 & $\mathbf{4 . 8}$ & 298 & 74.8 & 164 & 277 & $\mathbf{0 . 9}$ \\
'97 & 254 & $\mathbf{1 6 . 1}$ & 213 & 85 & 128 & 240 & 1.1 \\
'98 & 178 & $\mathbf{4 4 . 3}$ & 99 & 77.8 & 60 & 148 & 1.5 \\
'99 & 35 & $\mathbf{6 0}$ & 14 & -- & 11 & -- & -- \\
\hline \hline
\end{tabular}

Table V: Participation in the Gastroenterology Match. For each year, Positions Advertised is the number of positions whose availability in the match was announced in late March. Until late May, the programs may add or withdraw positions (Percent Withdrawn), which leaves the final number of positions in the match (Posititions in Match.) Percent Matched is the percentage of positions in the match that are filled by the match. Number of Applicants is the total number of applicants who listed at least one GI program in their rank order list.

If a simple shift in supply or demand were enough to cause a match to collapse once it had become successfully established, many other markets, including other internal medicine subspecialties, would also have failed matches, since these shifts turn out not to be so rare. What was unusual about the change that the gastroenterology match

${ }^{20}$ Dr. David Brenner, quoted in Gerson (1999), described that demise in part as follows: "Many applicants and a large percentage of the fellowship programs stopped using the match, which made choices more difficult for the remaining applicants and programs and created a vicious circle. Many training directors were very disappointed a few years ago when they didn't fill their slots because the applicants they thought were interested accepted positions before the match.” 
experienced in 1996 was that it temporarily reversed the traditional excess supply of applicants (in Table $\mathrm{V}$, the ratio of applicants to positions in the Match dropped below 1 in 1996). None of the other internal medicine subspecialty matches (Cardiovascular Disease, Pulmonary Disease and Infectious Disease) experienced such a shift. Infectious Disease successfully operates a match in which there are persistently fewer applicants than positions. $^{21}$

There are limits to the confidence with which one can draw conclusions simply by studying the circumstances in which rare events (like the collapse of a stable match) occur. So, one way to gather more evidence is to create small artificial markets in the laboratory, and subject them to controlled changes in supply and demand. McKinney, Niederle and Roth (2005) find in the laboratory that anticipated shifts in supply in demand, visible to both sides of the market, do not cause declines in match participation anywhere near the magnitude caused by unanticipated shocks, particularly when these are more visible to one side of the market than to the other. In particular, they consider shifts in demand for positions which are either visible to both firms and workers, or only to firms (as when an unexpected change in demand becomes visible to firms when they receive few applications, but not to workers). They find that demand reductions of both kinds cause firms to try to make more early hires, but that when workers know that they are on the short side of the market they are more likely to decline such offers than when they are unaware of the shift in demand. It is the combination of firms making early offers outside of the match, and workers not feeling safe to reject them and wait for the match that causes the market to unravel in the experiment. That is, the experiment shows that this combination of events can by itself be sufficient to cause the breakdown of a match. The results are thus suggestive that the same combination of events in the late 1990’s caused the breakdown of the GI match.

On the basis of these results, McKinney et al. conjecture that the breakdown in the GI market in 1996 was due to the unusual shock that caused an unanticipated reversal in

\footnotetext{
${ }^{21}$ From 1990 to 1998 the ratio of applicants to positions offered in the Cardiovascular match varied from a high of 1.6 to a low of 1.3. For Pulmonary Disease those ratios varied from a high of 1.5 to a low of 1.1, and for Infectious Disease (from 1994 to 1998) those ratios vary from a low of .68 to a high of .92. Thus, unlike in the Gastroenterology market, the short side of these markets did not change, although in Infectious Diseases the applicants were in short supply, and in the other matches the positions were in short supply (Niederle and Roth 2004).
} 
the short side of the market, with many fewer high quality residents wishing to start a GI fellowship. This increased incentives for programs to try to capture those GI fellows early. And because the shock was unusual, and not predicted, remaining residents may not have felt safe to reject early offers.

The evidence supported the conjecture that now that market conditions had stabilized, a match could once more be successful.

\section{IV.B. BEyOND CENTRALIZEd MATChing: Why DO SOME MARKETS WORK WELL, WHILE OTHERS DO NOT? HOW TO RESTART THE GI MATCH?}

The market for GI fellows seems to have broken down due to an unusual event, and then once more experienced unraveling and congestion. Clearinghouses solve both problems: they bring participants to the market at the same time, and they overcome congestion. This helps to make it safe for participants to act according to their preferences over other participants, without additional constraints on behavior imposed by inferior market organization. The supply and demand for GI fellowships had stabilized in the interim, and many participants on both sides of the market wanted to have a match once again, so all seemed favorable for a successful restart

To assess the demand by fellowship programs for a restart of the match, the questionnaire we administered to GI program directors in January 2005 (Niederle, Proctor and Roth 2006), also asked "Do you think a match would be better than the current system if most programs would adhere to it?”. Of the 60 responses, 50 said yes, and many of those who said no indicated that "most" would not be enough for them to have confidence in the match.

Following the announcement of the new GI match, communications from program directors confirmed that this was a lively concern, with some expressing concern about specific programs they regard as competitors. ${ }^{22}$

\footnotetext{
${ }^{22}$ In June 2005, our colleague Debbie Proctor, the gastroenterologist who took the lead in reorganizing the match, sent us an email saying, in part "I'm answering 3-4 emails per day especially on this issue. 'I want to make sure MY competition is in the match and that they don't cheat.' Well, this is another way of saying that if they cheat, then I will too!...Have you ever seen this before? The distrust amongst program directors? I find it hard to believe that we are unique. Maybe this is [a] social science phenomenon?”
} 
Program directors who wished to participate in the match worried that if their competitors made early offers, then applicants would lose confidence that the match would work and consequently would accept those early offers, because that had been the practice in the decentralized market. That is, in the first year of a match, applicants might not yet feel that it is safe to reject an early offer to wait for the match. Program directors who worried about their competitors might thus be more inclined to make early offers themselves. Recall that, before the reintroduction of the match, many program directors sped up offers because they felt pressured by applicants who were disappearing from the market in response to the early offers of other programs.

This raises the more general question as to why some markets unravel and experience congestion problems in the first place (and hence are good candidates for introducing a centralized match), and what are good policies to make markets operate at a later time.

Empirically, most markets that have been observed unraveling are markets in which employers make short duration offers, and in which the acceptance of an offer is binding (see Niederle and Roth 2008; for a description of the market for law graduates seeking employment as appellate court clerks see Avery, Jolls, Posner and Roth, 2001, 2007, and for college admissions see Avery, Fairbanks and Zeckhauser 2003). ${ }^{23}$

On the other hand there are markets that do not unravel, such as the market for graduate school admission. In this market, a policy (adopted by the large majority of universities) states that offers of admission and financial support to graduate students should remain open until April 15.

Students are under no obligation to respond to offers of financial support prior to April 15; earlier deadlines for acceptance of such offers violate the intent of this Resolution. In those instances in which a student accepts an offer before April 15, and subsequently desires to withdraw that acceptance, the student may submit in writing a resignation of the appointment at any time through April 15. However, an acceptance given or left in force after April 15 commits the student not to accept another offer without first obtaining a written release from the institution to which a commitment has been made. Similarly, an offer by an institution after April 15 is conditional on presentation by the student of the written release from any previously accepted offer. It is further agreed by the institutions and organizations subscribing to

\footnotetext{
${ }^{23}$ Since 2003, the market for law clerks has succeeded in moving hiring new graduates nearer (by a year) to the date of graduation (and the beginning of employment). But exploding offers with binding agreements have kept the market very thin (Avery, Jolls, Posner and Roth, 2007 and Haruvy, Roth and Unver 2006).
} 
the above Resolution that a copy of this Resolution should accompany every scholarship, fellowship, traineeship, and assistantship offer.

This of course makes early exploding offers much less profitable. A program that might be inclined to insist on an against-the-rules early response is discouraged from doing so in two ways. First, the chance of actually enrolling a student who is pressured in this way is diminished, because the student is not prevented from later receiving and accepting a more preferred offer. Second, a program that has pressured a student to accept an early offer cannot offer that position to another student until after the early acceptance has been declined, at which point most of the students in the market may have made binding agreements.

Niederle and Roth (2008) study in the laboratory the impact of the rules that govern the types of offers that can be made (with or without a very short deadline) and the commitment of applicants upon accepting an offer. Firms decide when and to whom to make offers, while information about the quality of applicants is only revealed over time. In these small environments, designed so they are not prone to congestion, either eliminating the possibility of making exploding offers, or making early acceptances nonbinding, helps prevent markets from operating inefficiently early.

In practice, it is very hard to enforce the time at which programs make offers and how long offers are left open. The policy of making acceptances non-binding instead helps the applicants themselves deal with such early and short offers. Because applicants can accept these offers without compromising their availability for subsequent offers from programs they prefer, no program need feel pressured to make an early offer itself just because another program is doing so.

We proposed a similar policy, adapted to the situation of the upcoming GI match (Niederle, Proctor and Roth 2006). Ideally, such a policy would remove any temptation for fellowship programs to extend early offers and ask for a response before the match, by allowing applicants who had accepted early offers nevertheless to participate in the match. Under such a policy, an applicant who had accepted a prematch offer would be able to enter the match, listing only programs he or she preferred to the early offer. The match result would be binding, and if the applicant were successfully matched, he or she would then be freed from his or her prematch commitment and able to fulfill his or her 
commitment to the match. Under such a policy, programs would have little incentive to ask for prematch agreements, because doing so would give them no advantage in “capturing” candidates who would have preferred to consider all the options available in the match and await the match outcome. Note that programs would not lose in any way the ability to attract candidates who genuinely regarded them as their first choice, because any program and applicant who list each other first in the match are guaranteed to be matched to one another.

A modified version of this policy was adopted by all four major Gastroenterology professional organizations, the American Gastroenterological Association (AGA), the American College of Gastroenterology (ACG), the American Society for Gastrointestinal Endoscopy (ASGE) and the American Association for the Study of Liver Diseases (AASLD), regarding offers made before the (new) match. While it doesn't allow applicants who have accepted early offers to participate in the match before declining those offers, it does allow them to decline early offers and then participate in the match. It states, in part

The general spirit of this resolution is that each applicant should have an opportunity to consider all programs before making a decision and be able to participate in the Match. ... It therefore seeks to create rules that give both programs and applicants the confidence that applicants and positions will remain available to be filled through the Match and not withdrawn in advance of it. This resolution addresses the issue that some applicants may be persuaded or coerced to make commitments prior to, or outside of, the Match. ... Any applicant may participate in the matching process ... by ... resigning the accepted position if he/she wishes to submit a rank order list of programs ... The spirit of this resolution is to make it unprofitable for program directors to press applicants to accept early offers, and to give applicants an opportunity to consider all offers ${ }^{24}$

The gastroenterology match for 2007 fellows was held June 21, 2006, and succeeded in attracting 121 of the 154 eligible fellowship programs (79\%). 98\% of the positions offered in the match were filled through the match. Niederle, Proctor and Roth (2008) show that in the second year of the new centralized match the interview dates were successfully pushed back and are now comparable to those of other internal medicine

\footnotetext{
${ }^{24}$ http://www.gastro.org/userassets/Documents/04_Education_Training/Match/Match_Resolution_Nov_5_05_final.pdf
} 
specialties that have used a centralized match for many years. Furthermore, there is considerable enthusiasm for the new match.

\section{IV.C. OTHER EFFECTS OF THE GI MATCH:}

There is an additional unexpected advantage of the match. It changed not only the timing but also the nature of interviews between candidates and fellowship programs (Niederle, Proctor and Roth 2008). Interviews conducted prior to the match were more informative than those that had been conducted as part of the decentralized hiring process, and not only because they are now conducted later in applicants' careers, and hence with more information. The early impression is that the fact that interviews no longer lead immediately to offers changes the interaction: Candidates are more relaxed, less anxious to please, and the discussion is more focused on the fellowship and the candidate, i.e. on the transfer of information relevant to evaluating the quality of the match between that candidate and that position.

A further advantage of using a centralized match, briefly mentioned above, is that a match also allows for programs to flexibly fill different kinds of positions. The GI fellowship match has been set up through the NRMP/SMS so that programs may offer 4 different tracks or categories through the match: (1) clinical, (2) clinical investigator research, (3) basic science research, and (4) research. Each track in every program is given a unique identifying code number by the NRMP/SMS. For each track, a program will submit a separate rank order list of applicants in preferred order. Furthermore, the program can specify that if it does not fill all of its available positions for one of its tracks, the position(s) can be reverted (i.e. reassigned) to one of the other tracks. In particular, by using the flexibility of the reversion algorithm, the match removes the

pressure on programs to fill research positions early because, if a research position cannot be filled, it can automatically be converted into a clinical position.

Note that the move to a match does not appear to be a Pareto improvement: not all prospective GI fellows and GI program directors benefit from a match compared to a decentralized market. Recall that a decentralized market is a very local market, in which GI fellows were often internal medicine residents at the same hospital . In a more national 
market mediated by the match, therefore, some lower prestige programs that were accustomed to recruiting talented local residents may find that these residents can now go to more prestigious programs elsewhere. Indeed, there are GI fellowship programs that were not pressing for gastroenterology to rejoin the match, and preferred the market to operate in a decentralized way, for this reason (Ehrinpreis 2004). ${ }^{25}$

\section{Gastroenterology as a Case Study of Some General Phenomena}

The market for gastroenterology fellows provides a case study for the effects of a centralized match, and illustrates some challenges facing decentralized markets. As we've discussed, in periods in which it was decentralized, the market for gastroenterology fellows unraveled, but a centralized clearinghouse helped the market maintain thickness, avoided congestion, and with appropriate supporting rules about offers and acceptances, made it safe for applicants and employers to participate.

Which of the lessons learned from the GI market have relevance for other markets? And what makes markets prone to the problems faced by gastroenterologists, namely lack of thickness, congestion and lack of safety for market participants to act straightforwardly according to their preferences? While we were able to study the gastroenterology fellowship market in unusual detail, we observe many pieces of the pattern in other markets (cf. Roth and Xing 1994, 1997). Most recently we studied the market for orthopaedic surgery fellows, which shows patterns very much like the market for GI fellows (Harner et al. 2008).

Another market recently studied in detail is the market for law clerkships. A prestigious, and valuable career step for lawyers, after they finish the three years of law school, is to clerk for a senior federal judge. Over the past decades, the market moved from hiring students at the end of the third year to the beginning or middle of the second

\footnotetext{
${ }^{25}$ This was seen very clearly in the experimental results of McKinney et al. (2005). In the lab, unraveled markets were less efficient, and so there was less assortative matching. But this meant that some low productivity employers were matched with some frequency to higher productivity workers than they could attract at a stable match, and such employers do less well under a stable matching mechanism operated at an efficient time (see also Niederle and Roth 2008).
} 
year of law school. The past two decades have been characterized by a multitude of reforms that try to regulate the timing and nature of the hiring process. These lasted on average three years, and share the fact that they all failed, apart from the most recent attempt that is still ongoing (Avery et al 2007).

While most of the market is now officially coordinated to make offers only after a specific point in time (most recently, this was Monday two weeks after Labor Day), the market is still thin. Most offers are exploding offers, which are often accepted instantly (even when they aren't from the most preferred judge who offered an interview), resulting in a market that moves very fast. Because congestion has not been solved and exploding offers are still ubiquitous, a large proportion of applicants only receive one offer, and many judges do not make multiple rounds of offers. This is not a marketplace in which applicants can safely wait for more desirable offers, or judges can wait to make offers until they interview all candidates.

Hence, moving a market to an agreed upon time window is not sufficient to solve problems of thickness, congestion and safety. Indeed, the market appears to once more be experiencing some unraveling. Many judges have made offers shortly before the allowed time. Those who do so have access to a large applicant pool, and no information on applicants is lost by moving only a few days early.

Another well studied market that experienced problems similar to those in gastroenterology is the very small market of post-season college football games, called “bowls” (Roth and Xing, 1994 and Frechette, Roth and Unver, 2007). In the early 1990’s, the determination of which teams would play each other in which bowls was often made when several games still remained to play in the regular Fall season. Most bowls had long-term contracts with football conferences, at least for one of the two teams that would play in their post-season bowl game, and had to recruit the other team. The National Collegiate Athletic Association (NCAA) tried for years to prevent the unraveling of the dates at which bowls and teams finalized agreements about which teams would play in which bowls. However it gave up in failure following the 1990-91 football season, in which early matching - when there were still 4 games left to play in the regular season - (once again) led to poorly matched teams. (A team that looks like a champion with four games still left to play will not look as good at the end of the season 
if it has lost some of those games.) Starting in 1992, a series of reforms eventually led to a reorganization through the Bowl Championship Series (BCS) in which a consortium of four bowls (Rose, Fiesta, Orange and Sugar) and six athletic conferences agreed to do the matching of teams to bowls only after the conclusion of all regular season games, and always allow for a matchup in one of the participating bowls between the two highest ranked teams in the BCS rankings. Frechette, Roth and Unver (2007) show that the missed championship matchups (i.e. the number 1 team playing against the number 2 team according to the Associated Press (AP) Sports Writers' end of regular season rankings) in the pre-coalition era were due not only to precommitments of conferences to bowls, but largely also due to in-season unraveling that led to the selection of teams while games were still to be played. ${ }^{26}$ Matchups between top ranked teams has significantly increased in the coalition era, which has led to more viewers as measured by Nielsen ratings of the televised games. To the extent that the number of viewers is a measure of the output of this industry, this means that the changes in market organization that led to later and improved matchings substantially increased output and efficiency.

\section{V.A. DO PROBLEMS OF CONGESTION, THICKNESS AND SAFETY AFFLICT ONLY SPECIAL MARKETS ?}

How special is the market for GI fellows? Given the variety of markets that have experienced at least some of the failures that afflicted the GI fellows market, we consider some features of the market that we know are not special.

The size of the Market: The GI fellows market has about 300 fellows a year. The market for post-season college football bowls is substantially smaller, while the market for medical residents is much larger, with over 20,000 positions a year. An even larger market that has experienced significant unraveling is the market for college admission. In the late nineties, many highly ranked universities filled 40 to $60 \%$ of their slots through “early admission” (Avery, Fairbanks and Zeckhauser 2003). In "early admission”, as

\footnotetext{
${ }^{26}$ Four weeks prior to the end of the season the top 2 teams have only a 35\% chance to remain the top 2 teams at the end of the season, while it is $69 \%$ one-week prior to the end of the season (and $100 \%$ if the teams are picked after the conclusion of the regular season, Frechette, Roth and Unver, 2007).
} 
opposed to regular admission, students submit their applications around October or November, as opposed to January, that is, without information about their fall semester of their last year in high school. Most early admissions programs allow students to only apply early to one program, and some (called "binding early decision”) require students to agree to attend if accepted early. In this respect early college admissions is not only unraveled in time, but it also becomes a thin market in which at least some students can entertain no more than one offer of admission.

Entry level labor markets only? The market for college football bowls has suffered from problems of thickness, congestion and safety. ${ }^{27}$ So has the market for college admissions (although it shares some of the property of an entry level labor market).

Price regulated markets only? The market for college football bowls is a market in which prices are not regulated but which also suffered from unraveling. Similarly, in the late 1980's, the market for new law associates at large law firms substantially unraveled as summer associate positions increasingly became the channel through which new lawyers were hired, in a market that also showed active yearly wage competition (see Roth and Xing 1994).

\section{V.B. DisCUSSION}

It is worth spending a little time reflecting on why unraveled, congested markets fail to produce competitive, stable outcomes, i.e. why standard arbitrage and recontracting arguments fail. Suppose there is an outcome that is not competitive, why would a firm and a worker who would both prefer to be matched to each other not act on this, and match to each other as opposed to their current partner? There are (at least) two constraints commonly observed in naturally occurring markets. The worker may have agreed to some prior commitment and may not be free to change his mind. Alternatively,

${ }^{27}$ Li and Rosen (1998), Li and Suen (2000), and Suen (2000) show how unraveling can occur as a form of insurance in competitive markets. In their models, markets clear early but remain competitive. In the markets we study, the decentralized markets do not appear to be well modeled as perfectly competitive markets.See also Halaburda (2007) who models unraveling as a function of how correlated are the preferences of firms for workers. 
if firms have a limited number of positions, the firm may have already hired another worker, who it cannot fire at will, or easily, or without loss of reputation. Then why did the firm and the worker make these prior commitments in the first place? For firms and workers to realize their best possible outcomes, the market has to transmit sufficient information to allow firms and workers to determine their stable match partner without first engaging in binding commitments. Much of the benefit of a market has to do with bringing together many buyers and sellers at the same time, so that they can consider a wide range of possible transactions. This is however not what happens in unraveled markets that experience exploding offers: In such markets participants are not able to gather information about multiple options and then act on that information to seek out their most preferred alternatives. Choices must be made from a very small set of alternatives and in a short period of time. Decisions are reached on the basis of very limited information.

While there are not many detailed models of congested decentralized markets, Niederle and Yariv (2008) show theoretically how exploding offers, even in markets in which no other frictions are present, in general do not allow participants to reach a stable outcome. The problem is that the transmission of information is reduced compared to markets in which offers are tendered without a binding deadline. ${ }^{28}$

This description of obstacles to a stable outcome suggests that markets that are especially prone to unraveling are markets in which frictions are important, such as high costs of making an offer, or a long time required to make an offer (or a high cost of waiting for some participants). It may also be that markets in which employers are not very flexible in the number of workers they can hire are especially vulnerable to the difficulties caused by congestion. Recall, e.g. the college football bowls: in a market in which transactions are made early, there are costs to waiting too long to try to engage a team, as good teams may become committed to other bowls. Neither can a bowl simply add a third team to its game because it turns out that a good team was overlooked early in the market. That is, a bowl needs to field exactly two teams. Similarly, medical residency and fellowship programs have inelastic demand for residents and fellows, because of the

\footnotetext{
${ }^{28}$ See also Segal (2007) on the information needed to determine if an outcome is stable..
} 
way that funding and sometimes accreditation of those programs are determined by their ratio of doctors to patients.

In contrast to markets in which the number of contract partners is strictly limited, in the market for graduate students most departments are somewhat flexible as to the number of students in their incoming class. This may be the main reason that they can successfully use the Council of Graduate Schools policy that promotes open offers to regulate the timing of their market (see Section IV.B.).

In the market for GI fellows, a similar policy was successful in combination with a centralized clearinghouse to solve the congestion problem. Since, fellowship programs have quite inelastic demand for fellows, it is likely that, in the absence of a clearinghouse, a policy promoting open offers would have been insufficient. Before adopting a centralized match, the market for residents tried a policy of advocating open offers, but failed, because of the congestion which resulted when many offers all had deadlines at roughly the same time, so that employers whose offers were rejected found that most applicants had already accepted positions (Roth 1984, 2003).

In addition to markets in which the number of positions is very inflexible, many markets that experience unraveling are also markets in which there is important heterogeneity. Consider once more the market for college football bowls: there is a very important difference between the best team and the third best team, not to mention the $17^{\text {th }}$ best. If all teams were the same, the problem of finding a good match of bowls and teams would be much more tractable. But because viewership is driven most by the chance to see the number one ranked team play the number two ranked team, bowls were willing to tolerate considerable risk to sign up early teams that might be number one or two when the season ended.

It appears therefore that markets in which there is not a high degree of flexibility in the number of positions, and in which heterogeneity is important, are markets that may be particularly susceptible to problems associated with thickness, congestion and safety. Entry level labor markets for elite professionals often seem to fit this profile, particularly when the simultaneous entry of many new workers (e.g. upon graduation from medical or law school) exacerbates potential congestion since many workers have to be matched at the same time. 


\section{Do Centralized Markets Increase Efficiency?}

There are several levels of efficiency that can be considered. Simple Pareto efficiency is hard to violate: for example, in a market in which all sides agree on which are the good jobs and the good candidates, a matching that assigns the worst candidates to the best jobs is still Pareto efficient, as an assortative match would make low quality candidates worse off. It is very hard to gather data on narrower notions of efficiency, e.g. to measure if an unraveled market lowers the total welfare or productivity of gastroenterologists compared to a centralized match. It is however the case that the majority of fellows and program directors welcomed the new system.

This is why it was useful to study college football bowls, in which the coalition era led to an increase in viewership, a reasonable proxy for output. In laboratory experiments too, total welfare (sum of earnings) is in general lower for unraveled markets, due to the costs imposed by unraveling (either direct costs, or costs due to inefficient matchups, when hiring occurs before the final quality of applicants is known, Niederle and Roth 2008).

Thus, although we often cannot measure efficiency loss due to unraveling, we have found inefficiency when we can measure it.

\section{Why do only some markets organize through a centralized clearinghouse?}

Most markets that are organized through a centralized clearinghouse are markets that both (i) experienced very severe unraveling or congestion, in which the resulting inefficiencies were very widely felt; and (ii) have a strong set of market organizations and institutions that were able to effectively coordinate market participants. This is certainly true for many medical labor markets that use a centralized match. ${ }^{29}$

\footnotetext{
${ }^{29}$ The absence of a single strong professional society is presently making it somewhat difficult to change the market organization in the currently unraveled market for orthopaedic surgery fellows. There are multiple orthopaedic subspecialties that hire similar fellows. This is in contrast to the gastroenterologists, in which the American Gastroenterology Association had the largest number of members, and managed to coordinate with three other professional organizations on adopting a match, and appropriate policies to foster it.
} 
While the sizable number of markets that use a centralized clearinghouse is still only a small proportion among all entry level labor markets, many markets do experience problems of thickness, congestion and safety. This means that employers, when making offers not only have to assess how much they like each worker, but also how likely it is that the worker will accept an offer. This is because offers often have opportunity costs, because there are only a fixed number of positions, and the market moves ahead, that is, the pool of applicants for future offers becomes smaller over time, sometimes very rapidly. That is there are costs to making offers that get rejected, since, in the meantime, other desirable candidates may have accepted commitments elsewhere.

Some markets that experience congestion and unraveling sometimes seek relief through other means than a centralized clearinghouse: they try to facilitate the process of transmitting information about how much candidates are interested in potential employers (see e.g. Roth and Xing 1997 and Coles and Niederle 2008). In the economics junior market (for new Ph.D.s), congestion is an issue when deciding which subset of about 30 applicants to interview at the ASSA meetings. Many departments face real constraints, as they have "too many" outstanding candidates they could interview, but need to make sure they also interview candidates that they would have a chance to hire later on. In this market it has been common that letters from advisors often would transmit specific interest for a place, or maybe even a country or continent. Last year, the AEA ${ }^{30}$ instituted a centralized signaling facility, which applicants could use to credibly transmit signs of interest to employers, by allowing each job candidate to send a signal to at most two potential employers. This was used extensively, about 1000 job candidates used the service in the year 2006-2007 (see Roth, 1998).

\section{Market failure and market design}

Markets of all sorts need to provide thickness, deal with congestion, and make participation safe. Market failures often involve the failure to accomplish one or more of

\footnotetext{
${ }^{30}$ Through its Ad Hoc Committee on the Job Market (Alvin E. Roth, chair, John Cawley, Philip Levine, Muriel Niederle, and John Siegfried). See http://www.aeaweb.org/joe/signal/signaling.pdf .
} 
these things. How such failures can be fixed, however, often depends on the details of the particular market in question.

Consider again the problem of coordinating a market around a centralized clearinghouse, as opposed to having employers make early offers in a decentralized way. In the gastroenterology fellows market, the four relevant professional associations did not feel they could prevent program directors from making early exploding offers, but they did believe that they could effectively empower applicants to deal with such offers by allowing them to change their minds later. This was effective in moving the market from early exploding offers at dispersed times to wide participation in a clearinghouse.

Orthopaedic surgery fellows face a very similarly unraveled market, with early offers at dispersed times (Harner et al. 2008). There is considerable doubt in that community, however, whether a policy allowing applicants to change their minds about accepted early offers would be as effective as it has been in gastroenterology. (Among other things, there is doubt that junior surgeons would feel able to break promises to senior surgeons even if this was sanctioned by the professional societies.) However, unlike the case in the gastroenterology market, a number of the orthopaedic surgery professional organizations feel that they could police the behavior of program directors, and effectively prevent them from making early offers, by imposing sanctions on offenders. Thus it is possible that the path to a labor clearinghouse in the orthopaedic surgery market may be different from the one in gastroenterology. (This transition may also be complicated by the fact that there are 15 professional organizations involved, rather than just 4.)

The problems faced by federal judges who wish to reform the perennially chaotic market for clerks is made more difficult by the fact that they face a combination of the problems that confront gastroenterologists and orthopaedic surgeons. Like the gastroenterologists, judges have no professional organization that is able to prevent early offers by judges. Like the orthopaedic surgeons, judges may not be able to adopt any policies that would effectively allow law students to change their minds after having accepted an early offer. 
(In fact, in that market, not only do law students not feel free to change their minds about accepted offers, often they do not feel free to decline the first offer they receive; cf. Avery et al. 2001, 2007 and Haruvy et al 2006.)

Sometimes, policies that might promote a centralized clearinghouse face objections having nothing to do with feasibility. In the market for clinical neuropsychologists, a policy empowering applicants to change their minds after accepting an early offer seems feasible in principle. However, there are strong feelings on the part of some involved that such a policy would be repugnant. The current president of the relevant professional organization said in an email "I have said it once, and I will say it again: Two wrongs do not make a right. To state it another way: The end does not justify the means. I will be strongly opposed to any attempt at [a]... policy that allows candidates to accept an offer outside of the match, participate in the match anyway, and then renege on their earlier "acceptance".” Constraints imposed by repugnance towards certain kinds of transactions may be as powerful as constraints imposed by the nature of the market, and have to be taken seriously by market designers (see Roth 2007).

While the underlying problems are similar in the four markets discussed above, namely to ensure that offers and acceptances are made in a late, centralized market, the possible solutions and policies to achieve that depend on the details of the market, including constraints given by the structure of the market as well as its social norms.

\section{CONCLUSIONS}

The market for gastroenterology fellows provides a case study of market failure, and of the ways in which centralized clearinghouses can sometimes fix them. It appears that labor markets, and other heterogeneous markets, can suffer from congestion, which can in turn lead to strategic behavior that can result in lack of thickness and add risk to straightforward participation in the market. Consequently these markets may not always function efficiently when left to their own devices, but may need market institutions to facilitate commerce. Professional organizations can sometimes play a useful 
intermediary role in establishing and maintaining such institutions. More research is needed to try to understand how labor markets work in detail, so that we can better understand when they work well, and can fix them when they are broken. 


\section{REFERENCES}

1. Avery, Christopher, Andrew Fairbanks and Richard Zeckhauser, The Early Admissions Game: Joining the Elite, Harvard University Press, Cambridge, MA 2003.

2. Avery, C., Jolls, C., Posner, R. A., and Roth, A. E. (2001), "The Market for Federal Judicial Law Clerks," University of Chicago Law Review, 68:793-902.

3. Avery, Christopher, Jolls, Christine, Posner, Richard A. and Roth, Alvin E., "The New Market for Federal Judicial Law Clerks" . University of Chicago Law Review, 74, Spring 2007, 447-486.,

4. Bauer, William T., William Fackler, Kavita Kongara, Christie Matteoni, Bo Shen and Michael Vaezi, Comment to It's Time to Bring the Best and Brightest Back to Gastroenterology, Gastroenterology 116, 4, 1999, 1014.

5. Bulow, Jeremy and Jonathan Levin. 2006. "Matching and Price Competition." American Economic Review, 96(3), 652 - 668.

6. Coles, Peter and Muriel Niederle, "Signaling in Matching Markets", preliminary working paper May 2007.

7. Ehrinpreis MN. "Con: the gastroenterology fellowship match: R.I.P." American Journal of Gastroenterology 2004;99:7.

8. Fréchette, Guillaume, Alvin E. Roth, and M. Utku Ünver, "Unraveling Yields Inefficient Matchings: Evidence from Post-Season College Football Bowls,” Rand Journal of Economics, 38, 4, Winter 2007, 967-982.

9. Gale, David, and Lloyd S. Shapley. 1962. "College Admissions and the Stability of Marriage." American Mathematical Monthly, 69, 9-15.

10. Gerson, Lauren, To Match or not to Match in Gastroenterology: An interview with David Brenner, MD, Chair of AGA's Manpower and Training Committee, AGA Trainee \& Young GI news, Spring 1999, Volume 5, Number 1, http://www.gastro.org/trainee/trainee6.html

11. Halaburda, Hanna W. "Unravelling in Two-Sided Matching Markets and Similarity of Preferences." December 2007.

12. Harner, Christopher D., Anil S. Ranawat, Muriel Niederle, Alvin E. Roth, G. Paul DeRosa, Peter J. Stern, Shephard R. Hurwitz, William Levine, Derena Hu, "Current state of fellowship employment: Is a match necessary? Is it possible?”, Journal of Bone and Joint Surgery, 90, 2008,1375-1384.

13. Haruvy, Ernan, Alvin E. Roth, and M. Utku Ünver, "The Dynamics of Law Clerk Matching: An Experimental and Computational Investigation of Proposals for Reform of the Market," Journal of Economic Dynamics and Control, 30, 3 , March 2006, Pages $457-486$.

14. Immorlica, Nicole and Mohammad Mahdian, "Marriage, Honesty, and Stability," SODA 2005, 2005, pp. 53-62.

15. Kagel, J.H., Roth, A.E., 2000. The dynamics of reorganization in matching markets: a laboratory experiment motivated by a natural experiment. Quarterly Journal of Economics 115 (1), 201-235.

16. Kelso, Alexander S., and Vincent P. Crawford. 1982. "Job Matching, Coalition Formation, and Gross Substitutes.” Econometrica, 50(6), 1483 - 1504. 
17. Kojima, Fuhito. 2007. "Matching and Price Competition: Comment", American Economic Review, 97(3), 1027-1031.

18. Kojima, Fuhito and Parag A. Pathak, "Incentives and Stability in Large Two-Sided Matching Markets", American Economic Review, forthcoming.

19. Li, Hao, and Rosen, Sherwin. "Unraveling in Matching Markets." American Economic Review. 88 (June 1998): 371-87.

20. Li, Hao, and Suen, Wing. "Risk Sharing, Sorting, and Early Contracting." Journal of Political Economy, 108 (October 2000): 1058-91.

21. McKinney, C. Nicholas, Muriel Niederle, and Alvin E. Roth. 2005. "The collapse of a medical labor clearinghouse (and why such failures are rare)." American Economic Review, 95(3), 878-889.

22. Meyer, Gregg S., et al. "Gastroenterology Workforce Modeling." Journal of the American Medical Association. 276 (September 4, 1996): 689-94.

23. Niederle, Muriel, "Competitive Wages in a Match with Ordered Contracts", American Economic Review , 97, 5, December 2007, 1957 - 1969. http://www.stanford.edu/ niederle/Niederle.OrderedContracts.pdf

24. Niederle, Muriel, Deborah D. Proctor and Alvin E. Roth. 2006. "What will be needed for the new GI fellowship match to succeed?" Gastroenterology, 130, 218-224.

25. Niederle, Muriel, Deborah D. Proctor and Alvin E. Roth. 2008. "The Gastroenterology Fellowship Match: The First Two Years," Gastroenterology, forthcoming.

26. Niederle, Muriel, and Alvin E. Roth. 2003a. "Relationship Between Wages and Presence of a Match in Medical Fellowships." JAMA, Journal of the American Medical Association, 290(9), 1153-1154.

27. Niederle, Muriel, and Alvin E. Roth. 2003b. "Unraveling reduces mobility in a labor market: Gastroenterology with and without a centralized match." Journal of Political Economy, 111(6), 1342 -- 1352.

28. Niederle, Muriel, and Alvin E. Roth. 2004. "The Gastroenterology Fellowship Match: How it failed, and why it could succeed once again." Gastroenterology, 127, 658-666.

29. Niederle, Muriel, and Alvin E. Roth. 2005. "The Gastroenterology Fellowship Market: Should there be a Match?" American Economic Review Papers \& Proceedings, 95(2), 372-375.

30. Niederle, Muriel, and Alvin E. Roth. 2008. "Making Markets Thick: Designing Rules for Offers and Acceptances." http://www.stanford.edu/ niederle/Thickmarkets.pdf.

31. Niederle, Muriel and Leeat Yariv, "Matching through Decentralized Markets", working paper, 2008.

32. Roth, A.E., "The Economics of Matching: Stability and Incentives," Mathematics of Operations Research, Vol. 7, 1982, 617-628.

33. Roth, Alvin E. 1984. "The evolution of the labor market for medical interns and residents: A case study in game theory." Journal of Political Economy, 92, 991-1016.

34. Roth, A.E., "The College Admissions Problem is not Equivalent to the Marriage Problem," Journal of Economic Theory, Vol. 36, 1985, 277-288.

35. Roth, A.E., "New Physicians: A Natural Experiment in Market Organization," Science, 250, 1990, 1524-1528. 
36. Roth, A.E., "A Natural Experiment in the Organization of Entry Level Labor Markets: Regional Markets for New Physicians and Surgeons in the U.K.," American Economic Review, Vol. 81, June 1991, 415-440.

37. Roth, Alvin E. 2002. "The Economist as Engineer: Game Theory, Experimental Economics and Computation as Tools of Design Economics." Econometrica, 70(4), 1341-1378.

38. Roth, Alvin E. 2003. "The Origins, History, and Design of the Resident Match." JAMA, Journal of the American Medical Association, 289(7), 909-912.

39. Roth, Alvin E. "Repugnance as a Constraint on Markets", Journal of Economic Perspectives, 21:3, Summer, 2007, pp. 37-58.

40. Roth, Alvin E. 2008 " Deferred Acceptance Algorithms: History, Theory, Practice, and Open Questions," International Journal of Game Theory, Special Issue in Honor of David Gale's 85 ${ }^{\text {th }}$ birthday, 36, March, 537-569.

41. Roth, Alvin E. "What have we learned from market design?" Hahn Lecture, Economic Journal, 118 (March), 2008, 285-310.

42. Roth, Alvin E. and Marilda Sotomayor. 1990. Two-Sided Matching: A Study in Game-Theoretic Modeling and Analysis. Econometric Society Monograph Series, Cambridge University Press.

43. Roth, Alvin E. and Elliot Peranson. 1999 "The Redesign of the Matching Market for American Physicians: Some Engineering Aspects of Economic Design." American Economic Review, 89(4), 748 - 779.

44. Roth, A.E. and X. Xing "Jumping the Gun: Imperfections and Institutions Related to the Timing of Market Transactions," American Economic Review, 84, September, 1994, 992-1044.

45. Segal, Ilya. 2007. "The Communication Requirements of Social Choice Rules and Supporting Budget Sets," Journal of Economic Theory, 136, 341-378.

46. Suen, Wing. "A Competitive Theory of Equilibrium and Disequilibrium Unravelling in Two-Sided Matching.” Rand Journal of Economics. 31 (Spring 2000): 101-20. 